Florida International University FIU Digital Commons

FIU Electronic Theses and Dissertations

University Graduate School

3-29-2016

\title{
We Are Standing in the Nick of Time: Translative Relevance in Anne Carson's "Antigonick"
}

Michelle Alonso

Florida International University, malon021@fiu.edu

DOI: $10.25148 /$ etd.FIDC000264

Follow this and additional works at: https:// digitalcommons.fiu.edu/etd

Part of the American Literature Commons, American Material Culture Commons, Book and Paper Commons, Classical Literature and Philology Commons, Continental Philosophy Commons, Dramatic Literature, Criticism and Theory Commons, $\underline{\text { Illustration Commons, Literature in English, }}$ North America Commons, Modern Literature Commons, Other Theatre and Performance Studies Commons, Performance Studies Commons, Translation Studies Commons, and the Women's Studies Commons

\section{Recommended Citation}

Alonso, Michelle, "We Are Standing in the Nick of Time: Translative Relevance in Anne Carson's "Antigonick"'" (2016). FIU Electronic Theses and Dissertations. 2509.

https://digitalcommons.fiu.edu/etd/2509

This work is brought to you for free and open access by the University Graduate School at FIU Digital Commons. It has been accepted for inclusion in FIU Electronic Theses and Dissertations by an authorized administrator of FIU Digital Commons. For more information, please contact dcc@fiu.edu. 


\section{FLORIDA INTERNATIONAL UNIVERSITY \\ Miami, Florida}

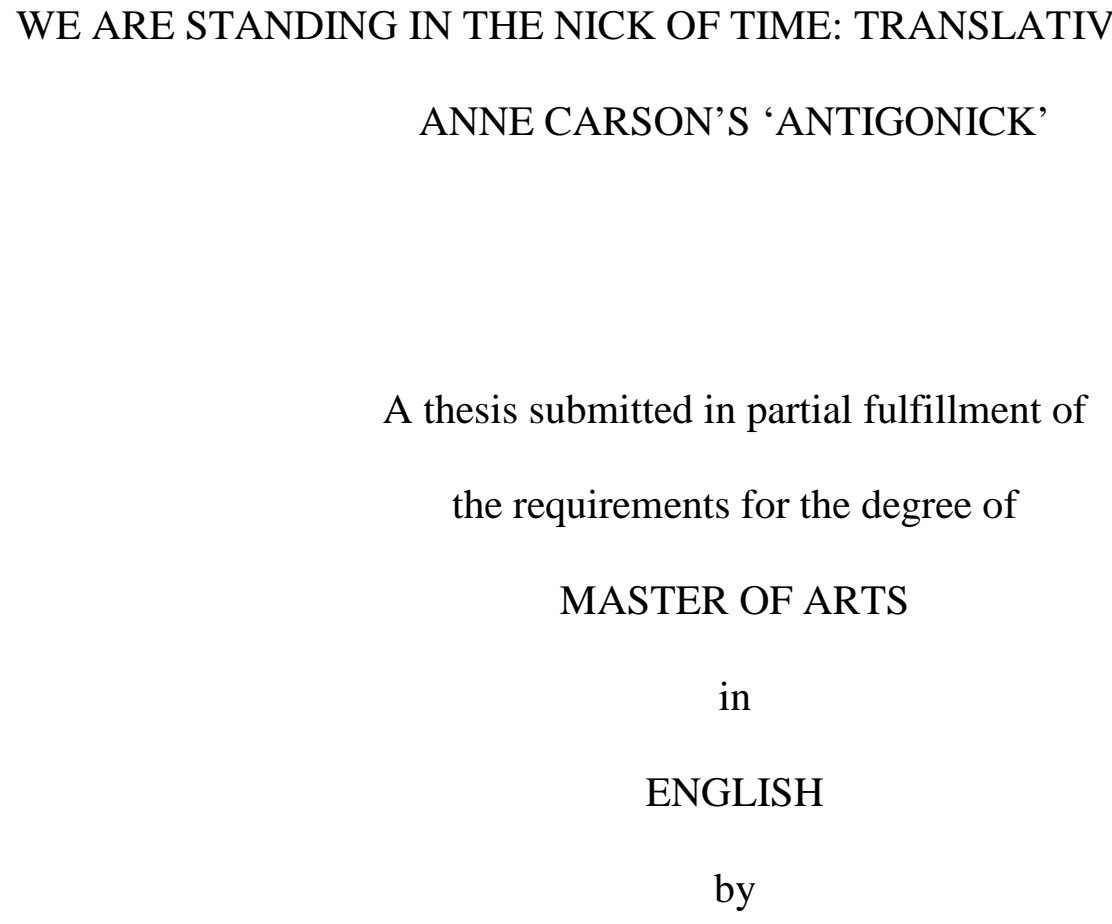

Michelle Alonso 
To: Dean Michael R. Heithaus

College of Arts, Sciences and Education

This thesis, written by Michelle Alonso, and entitled We Are Standing in The Nick of Time: Translative Relevance in Anna Carson's 'Antigonick', having been approved in respect to style and intellectual content, is referred to you for judgment.

We have read this thesis and recommend that it be approved.

$\begin{array}{r}\hline \text { Heather Blatt } \\ \hline \text { Maneck Daruwala } \\ \hline \text { Nathaniel Cadle, Major Professor }\end{array}$

Date of Defense: March 29, 2016

The thesis of Michelle Alonso is approved.

Dean Michael H. Heithaus

College of Arts, Sciences, and Education

Andrés G. Gil

Vice President for Research and Economic Development and Dean of the University Graduate School

Florida International University, 2016 


\section{DEDICATION}

For Tiffany, each the other's... \& for my father, in the wildest hope that we will meet again someday. 


\section{ACKNOWLEDGMENTS}

This thesis spent a lot of time in academic purgatory and it would probably still be stuck in limbo if not for the tireless efforts of Gala and Ginny - who roused me from my paralysis daily with their incessant barking...

All joking aside, I'd like to offer a special thanks to my mother who, despite our many differences, has found it in her heart to offer me her support in this and all of my projects. If translation has turned into an academic interest for me, it is only as the result of spending many days of my childhood with you, switching between languages, spilling over with secrets and anxieties - always aware of the edges and limitations of words. Nosotras somos y seguiremos siendo un equipo.

To my niece and nephew, who suffered childhood with me and lived to tell the tale and who continue to suffer alongside me, you are much appreciated (and no, you do not have to read this).

Furthermore, I will say with certainty that this thesis would have remained unfinished if not for my friends, whose dedication to this project and to my sanity has been proof of veritable human kindness. To Danny, my life-coach and the most painfully honest person I know, thanks for never letting me get too wordy or too full of commas. To Solsi, my late night proofreader, thanks for commiserating via chat in my self-imposed exile. To Craig, I am and have been lucky to have you in my corner.

In addition, the most heartfelt thanks go out to Heather Blatt, who told me once that my awkward entrance into research was perceived as graceful and seamless and who, five years ago, saw the potential for this thesis in an unremarkable undergraduate. Through the years, your encouragement and feedback have been invaluable. To Dr. McIntire and 
Dr. Daruwala, two of the kindest most sincere people I've ever had the pleasure of meeting, a million thanks would not be adequate.

And I would be remiss if I didn’t extend my warmest appreciation to Dr. Nathaniel Cadle for his integrity, his kindness, and his enduring friendship.

Now, T... trying to convey my gratitude for all of the sleepless nights, the kitchen fits of failure, and the gentle nudges in the right direction would be forcing me to confront the utter and absolute collapse of language. So, I won't. Instead, I hope it suffices to say; I am in awe of you always. 
ABSTRACT OF THE THESIS

WE ARE STANDING IN THE NICK OF TIME: TRANSLATIVE RELEVANCE IN

ANNE CARSON’S ‘ANTIGONICK’

by

Michelle Alonso

Florida International University, 2016

Miami, Florida

Professor Nathaniel Cadle, Major Professor

The complicated issues surrounding translation studies have seen growing attention in recent years from scholars and academics that want to make it a discipline and not a minor branch of another field, such as linguistics or comparative literature. Writ large with Antigonick, Carson showcases the recent Western push towards translation studies in the American academy. By offering up a text that is chaotic in its presentation, she bypasses the rigid idea of univocality. By giving the text discordant images, she betrays the failed efficacy of sign and signification, and by choosing a text to be performed and mutually participated in, she exceeds ideas of the individual subject as the site of authorship. Ultimately, Carson enacts a theory of translation that critically deconstructs translation itself. 


\section{TABLE OF CONTENTS}

CHAPTER

PAGE

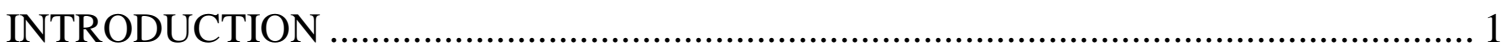

CHAPTER I: LIVING ON BORDER LINES: DERRIDA AND CARSON ON

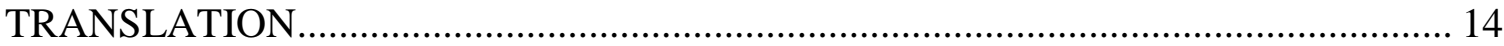

CHAPTER II: PAINTING THE SCREAM: STONE, CARSON AND IMAGES IN

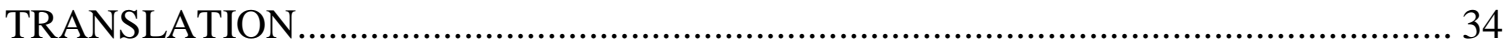

CHAPTER III: SEE OUR LIVES ON STAGE: PERFORMANCE AS

TRANSLATION, TRANSLATION AS PHILOSOPHY............................................. 49

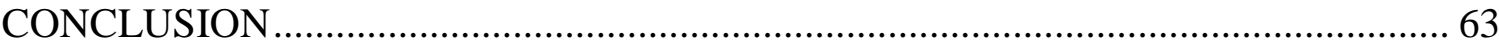

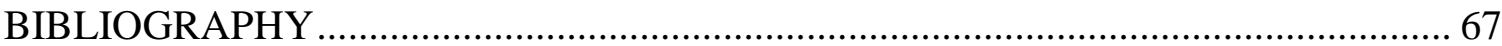

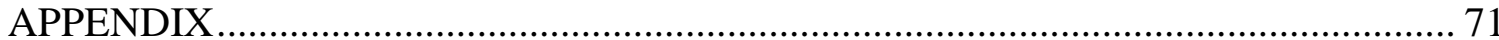




\section{INTRODUCTION}

"The face of theory has changed precisely through its cultural appropriations. There is a new venue for theory, necessarily impure, where it emerges in and as the very event of cultural translation... at the site where cultural horizons meet, where the demand for translation is acute and its promise of success uncertain.” - Judith Butler, Gender Trouble

Antigonick, Anne Carson's translation of Sophocles' Antigone, was released in 2012 to mixed reviews from columnists, critics, and disciples of Carson - all who felt that the manuscript was too tongue-in-cheek even when compared to her past publications. For books like the aptly titled Glass, Irony, and God (1995) or Eros: The Bittersweet (1986), Carson had employed her signature multilayered irony and pastiche to widespread critical acclaim. Yet many of the same elements that had previously garnered her accolades were the elements that critics condemned in Antigonick. Critics like Alexis Soloski called Carson’s "penchant for colloquialisms and modern day idioms" a "great distraction” (2) from the play’s essential message. Moreover, George Steiner claims that the inclusion of so many popular culture references and the "voice-overs by Hegel, Virginia Woolf and Bertolt Brecht" (5) exist only as a "facile diversion” (6) that detracts from what should be the translator's reverence towards the source text. In large part, these same critics cite Carson's desire to be intentionally circuitously referential and vague. They charge her with obscuring and obstructing the meaning of the original text, somehow barricading readers from arriving at what is essential and true about the work itself. Looking back, one can certainly see where Carson's past projects differ from 
Antigonick. Whereas books like Autobiography of Red (1998) and Eros: The Bittersweet had also dealt with a cultural repurposing of Ancient texts, they were original works birthed from otherwise obscure or forgotten fragments of Greek poetry, as opposed to what some critics would deem a complete and canonical text. The gaps between fragments allowed for Carson's intervention.

Antigonick is also not the first of Carson's works to deal with the many impasses of translation. In fact, Eros: The Bittersweet was conceived from a similar dilemma. Carson begins her doctorate's thesis by explaining that in the past, Sappho's lines about Eros had been mistranslated. To her, the delicate meaning behind Sappho's carefully chosen diction had been dismantled because translators had reversed the order of the compound word in Greek. Whereas Sappho’s adjective describing Eros in the original Greek fragment is sweetbitter, translators had continued to interpret the word with a replacement that would create the one-to-one correspondence between languages that is so desperately sought after in translations. Sweetbitter had been inverted and inserted into the text as the easily recognizable English word, bittersweet. Sequence, Carson argues, is most important in the understanding of this poem since Sappho organizes the fragment to recreate the very instant of desire. That love begins as paradoxically both sweet and bitter is the basis of Carson's subsequent dissertation where she maintains that it is Sappho's choice to locate "both poles of this affection within the single emotional event of Eros” illustrating the inherent and necessary paradox of human existence - the paradox of converging opposites. Carson's translative choice indicates both that language fails in its cliche - to call love bittersweet would label it with a word that is trite - and also that 
the translator is charged with a deep responsibility of inventing diction if it were so necessary in the host language to create the transparency necessary for translation. Carson calls on the power of interpretation to bring a word into existence where otherwise there would be cliche. Therefore, where language fails, the translator must find a new route in order to succeed. To translate Sappho otherwise would be negligent.

The focus of Eros is desire - a desire that stretches beyond the erotic and well into the very fabric of everyday reality. It is human nature "stirred to reach beyond perceptible edges” (Carson Eros 5), bound to reach for knowledge, for a lover, or for understanding only to realize that desire is a verb that requires an element of the unattainable in order to function as a consistently deferred action. Derrida's own text on translation was called Living On. Border Lines. which inevitably reminds of Carson's own obsession with the edges of things and certainly, there is a parallel to be drawn between the translator and the pining lover in Carson's Eros. There is, between the two, some thankless, answerless task that must be continuously revisited. The translator, in their desire, is relentlessly engaged in the act of courting the original work and trying to draw from it elusive but increasingly enticing meaning. As a trained Classicist, Carson has gone uncontested in this lifelong courtship until Antigonick. It seems that before Antigonick, there was a clear demarcation where Carson could interfere and fill in the gaps of what was unfinished, or color in the edges for the reader to see - a place that is ironically negated when it comes to the character of Antigone.

In the same way that Hamlet has come to stand in for the pitfalls of solipsism, so too has Antigone come to stand for the "slow and uncertain emergence of free 
subjectivity” (Soderback 224). This subjectivity that was once freeing for Antigone’s character has come to define her absolutely, barring transformation and cementing her in stiltedness. By captivating figures such as Hegel, Lacan, Heidegger, Butler and Cixous (to name a few), Antigone remains a staple of Western philosophy and as such she is, no doubt, treated with remarkable reverence. Her elevated status in academic and philosophical circles is made ever more apparent by critics' vehement rejection of Carson's manuscript and solidified by the visceral attitude of dismissal when it comes to the status quo: Antigone (and all interpretations of her) must remain frozen in time, unchanging. For these critics and academics mired in centuries' long tradition, there is nothing to be done to the word or form of Sophocles' original and readers must go on using those translations and interpretations that rely on outmoded archaisms in their quest to be perceived as an unmediated text.

Enter Carson, whose claim to literary fame is her ability to keep "always moving, and insisting that we continuously invent” (Anne Carson: Antigonick 16), with an autonomous Antigone in tow. With Antigonick, Carson brings readers a refreshing and unabashedly self-conscious take on a character who, in this translation, happily points fingers at her Western interpreters and calls out the likes of Brecht, Hegel, and Beckett. Surprisingly, Carson maintains that even these unconventional moves are part of a direct translation of the text (Anne Carson: Antigonick 16). Consonant with her reputation as a pioneer, and using colloquialisms, anachronisms, and pastiche, she playfully undoes notions of translation and completeness through Antigonick, a version of Sophocles’ play that is a far cry from other versions of the original in word or performance. The careful 
construction of Antigonick that juxtaposes text, image, and performance creates the perfect avenue for Carson to "present the enigma, or in other words, the recit of translation ... practically and in a sense performatively” (Ertel 6). It is through text, image, and performance that Carson interprets and enacts a philosophy of translation that complicates and clarifies the nuanced role of translations in creating and interpreting culture.

As mentioned previously, Carson claims nothing but the role of de facto translator, a move that opens the door to a reading that attempts to unravel some of the work she has arduously undertaken towards translation as performance - specifically as a meeting place for art and philosophy (or as it was so aptly labeled at the Sorbonne reading of the play in 2014, a philoperformance). This thesis seeks to outline the study of translation as a field that has evolved beyond a reading of symmetry or correlation between one language to another and, instead, is looking to become an academic category in its own right. I undertake this work with Carson’s Antigonick because I believe it exemplifies the concerns of translation studies while directly responding to the criticism lobbied against translation studies. Granted, Carson also uses Antigonick as a platform to grapple with very real thoughts and ruminations directed at the reader about collaboration, feminism, and the re-appropriation of problematic and beloved figures in literature, but I would say that all of these fragmented elements fit neatly into the work of translation - that they all surge from similar concerns about the evolving fields of communication and community- and that they can all benefit from a deeper look at the process of rendering canonical texts into other cultures. Translation itself is "intimately 
tied up with the context in which it is made,” (Bassnett-McGuire 20) a context which in 2012 saw the re-emergence of Antigone as a figure of political and civil resistance through works like Franklin Dominguez’s Antigona-Humor, that transforms Antigone into a political satire of the Dominican government, or the reawakened interest in Russian literary translations which has reversed the American Cold War-era interest in Russian literature by having progressive Russian translators take Western classics and translate them into Russian. These translations also appropriate the source text and, in a style similar to Carson's, subvert and adjust the words to call attention to the canonical sources.

The issues surrounding translation studies have also seen growing attention in recent years from scholars and academics that want to make it a discipline and not a minor branch of some other field such as linguistics or comparative literature. Whereas initial looks at translation focused on linguistic elements, current practice thinks of translation as "the transfer of meaning" through signs and symbols in a way that more closely resembles semiotics (McGuire 13). Since the practice is always seen as secondary to the act of creation, translation hides in the liminal space between generative act and mechanistic regurgitation, or exchange from one language into another. The field attempts to change the preconceived notion that translation is a study which requires little to no creative effort on the part of the translator or that it is a secondary and compulsory act that is less worthy than its original counterpart. Often, this marginalized and othered understanding of translation studies has afforded little in the way of academic economy, resulting in the emergence of criticism that purported to discuss translation while 
focusing only on the product, not the process. These critics completely overlook that the process invents the limits of the text in the first place and pushed the study further into the niche of "cultural and institutional marginality that limits the opportunities" of critics and scholars to study and write about translation (Venuti 237). Instead, translation studies looks to legitimize in its own way that which has been recognized time and again: the idea that language is cultural and circumstantial in its origins. A study of the process of translation that does not recognize this idea runs into the same essentialism that reduces the cultural practice of translation into a marginalized act.

Writ large with Antigonick, Carson showcases the recent Western push towards translation studies in the American academy. To use Antigone in this capacity and with this impetus is to erase and re-inscribe a text that "has already achieved canonical status" (Venuti 250) and to exemplify and deconstruct (to use Derrida's term) the issues that are currently involved in various scholarly debates. Through the palimpsest emerges a clear pattern of thinking. It is obvious that Carson must often wonder at length about translation considering that it has been the cornerstone of her work since she began learning ancient Greek in high school. Still, there is very little information about Carson's methods as a translator. A cursory MLA search with the terms Carson and translation will not yield much more than a few articles authored by Carson herself, and every one of her available interviews leaves untouched the process by which she renders the finished product. In one of the only interviews on the subject, granted to Alex Deuben of Shotgun Players, Carson said about Antigonick that "everything [she’s] done in the translation is an attempt to convey a move or shock or darkening that happens in the original text.” 
(Anne Carson: Antigonick 16) In fact, she makes the claim for transparency - the likes of which Derrida calls the "first duty of the host," which is to "speak a language that is intelligible and transparent, hence without equivocation” (Derrida 176). Derrida does not mean that translation is possible in the seamless manner of copying over one text from another but that a translator must make the unattainable a goal of his work. Derrida questions and does away with the notion that any "signification could be univocal," or in other words, the idea that meaning could ever be one or homogenized (Ertel 7).

Appropriately, it seems that Anne Carson has picked up where Derrida's work trails off - namely the employing of Derrida's philosophy on translation. Carson easily explains away any criticism asserting she has altered Sophocles' Greek. She is careful, as is her custom. In previous interviews or appearances, Carson has had her audience imagine the methodology behind her translations in vague metaphors: an image of shaking fragmented ideas around to an image of a box full of meat. For Carson, whatever spills out of the box, this pitiful offering of meat, becomes her work. She offers no explanation as to why those pieces of meat are in that particular box and why she is shaking it around in the first place and to the reader, then, the machinations behind her work must always look chaotic. Yet, the meticulous care with which she has assembled her manuscripts render a chaotic workspace impossible to conceive.

Because of its unconventional arrangement of word and image and unorthodox materiality, Antigonick recreates some of Carson's previous successes with form (see Anne Carson's memoir for her brother titled Nox, which took the form of a fragmented poem by Catallus, spliced within an accordion booklet), through a genre that has received 
little attention in translation studies - namely that of theater. Carson seems to be familiar with the idea that "a notion of theater that does not see the written text and performance as indissolubly linked will inevitably lead to discrimination against anyone who appears to offend against the purity of the written text” (Bassnett-McGuire 121) - a sentiment echoed by the kind of editorials that were written about Carson's work after Antigonick hit shelves. The bound manuscript includes pages of vellum drawn with watercolors that separate each page of text. These images are not literal correlatives of the text and were, according to the illustrator, Bianca Stone, produced in a period where she was not allowed to see any part of Carson’s translations (Anne Carson: Antigonick). Once produced, Robert Currie, who was a third collaborator on the project, randomly inserted the images into the text. The text contained in the manuscript itself is written in Carson's own handwriting - an effect that makes the words look as if bird talons had painstakingly etched the all-capital script in black ink. Emphasis, wherever needed, is created in red. Within the text, scenes are called episodes as a way to hearken back to the Greek episodio (but which could also simultaneously evoke the episodic nature of popular television dramas), brackets identify stage directions, and Carson deploys influences from Hegel to Beckett to Virginia Woolf. Like its predecessor, Sophocles’ Antigone, Carson’s text demands performance and like its’ predecessor, Antigonick is also steeped in its’ own history.

By placing her name in smaller script along the bottom left-hand edge of the front cover, she draws attention to the name of Antigone's Greek author, Sophocles. His name in bold, triumphantly graces the cover with spacing between the letters in typographic 
staccato. Even though the book is still under ' $C$ ' for Carson in bookstores and online, Carson honors the classical tradition of collaboration not only through her immediate work with Bianca Stone on the vellum plated images that are spliced into the text, but also through the work which she undertakes as Sophocles' translator. She does not shy away from the responsibility she represents on the cover page. Instead, she meets the question head on - almost as if asking to be challenged in a role that she has otherwise performed unquestioned. With precision, Carson places herself at the front line of bisecting arguments: Is the task of the translator to render a theatrical work into another culture through time, and how does this marginal study of text and performativity change the way in which we come into contact with texts as vehicles for timely truths?

When she claims the role of translator on the cover of the manuscript, Carson returns to the same model she employed in earlier works, such as An Orestia, where she assumed the marginal role of the oracular translator whose sole function is to channel the ancient words without changing their meaning. But by its very nature, translation involves the act of interpretation, of violent action taken against another’s language in order to render one text transparent to a new culture. If there were a one-to-one correlation between words in the source language and those in the translated language, the process would be different, mechanical, and simple. But unfortunately, there is much that is not transferrable from ancient Greek into modern English or, for that matter, from one language into any other. As notable translation critic Susan Bassnett-McGuire states, "No two languages are ever sufficiently similar to be considered as representing the same social reality. The worlds in which different societies live are distinct worlds, not merely 
the same world with different labels attached” (13); in other words, the social, cultural, and political realities of everyday life keep people from inhabiting the same space, and even if someone could potentially overcome these disparities, the case still stands that signification, far from being singular, has, in the world of postmodernism, been opened up to the idea of the many. Bassnett-McGuire's work pushes for academics to take into account the social and political contexts of translations surrounding both the source text and the culture of the language it is being translated into.

I believe that there is no timelier question in the twenty-first century than that of translation. We live in a world shocked into postmodernity, and ideas of the fragmented subject nudge us towards the recognition of gaps and edges instead of wholeness in an attempt to reconstitute and radicalize a world ruled over by totalizing normative structures, including those governing bodies that through their authority impose, perpetuate, and privilege the idea of transparency and fidelity in the quest for relevant translations. All the while, these same normative forces are able to ignore the fact that translation can only ever serve as a way to reinforce the instability of the text, thereby rejecting the fixity of language and buttressing the plurality of meaning. Carson's critics have claimed time and again that her writing “collapses the centuries” (Wakabayashi and Kotari 173). More often than not, they are concerned with how Carson moves forward towards postmodernism by dragging the classics along with her, so that the differences are no longer felt temporally an effect she achieves in Antigonick by translating the ideas faithfully but remaining judicious and firmly poised against an unnecessary perpetuation of arbitrary rules of translation. 
Moreover, Antigonick manages, through the fervent rejection of convention, to bring audiences back to the original in its strangeness. It is strangeness that theater critic Page Dubois recognizes is written into the very fabric of Greek theatrical life as polyphony - the very same polyphony that, concurrent with theories of translation, fulfills its role as the negotiator of two cultures. The choruses are the focus of Dubois' study of polyphony since they are "always anonymous" and develop for us the sense that just like language, the individual was all but shattered in Greek tragedy, a theory that is closer to our version of poststructuralism than it is to Lacanian or Hegelian thought. It is less the ideal space that theorists have envisioned and, in response, Dubois states that:

To read Greek tragedy, the tragic, as a discourse on the individual, even one conceived within the narrative of absolute spirit or incestuous desire, is to reveal perhaps a nostalgic desire for a sovereign, individual, heroic subject, one who can still make choices, even catastrophic ones that determine his or her fate, that exhibit will and efficacy now eroded. (Dubois 77)

Perhaps this is Carson's best-executed idea. By offering up a text that is already chaotic in its presentation, she bypasses the rigid idea of univocality. By giving the text discordant images, she betrays the failed efficacy of sign and signification, and by choosing a text to be performed and mutually participated in, she exceeds ideas of the individual subject as the root of translation. The transgressive in Antigone stands in for those ideas of cultural translation that seem so integral to academic criticism and the fabric of everyday life today. 
To examine translation in Carson, I will turn to the work of Jacques Derrida who asks that we think of translation as all of the potential afterlives of a text. A translation is always married to interpretation, and it is the translator's task to juggle the two. This thesis uses the two tasks interchangeably (translation and interpretation) not because they are technically synonymous, but because translation inevitably implies the act of interpretation. The translator should find that interpreting the work is utterly inescapable if he/she is to render the work in its most "relevant" form, says Jacques Derrida in his talk on translation titled "What is a Relevant Translation?” (75). Once the text at hand has lost its translatability, Derrida posits that the text has died an awful death - one shrouded in obscurity. Derrida, who according to critic and professor of French and French translations, Emmanuelle Ertel, was heavily involved with translation throughout his career, had only minor traction in the United States upon the subject. Nevertheless, Ertel makes a compelling case for the reexamination of Derrida's work related to translation. Among the titles directly linked to translation studies are Des Tours De Babel, which was an essay on Walter Benjamin's ${ }^{1}$ “The Task of the Translator” (1923), as well as a less well-known chapter in Right to Philosophy. This last obscure chapter is where Derrida presents and enacts the "tragedy of translation,” (Ertel 11) something that like Antigone's tragic dilemma must be produced in the borders and the gaps of meaning.

After discussing Derrida in conjunction with translation, I will discuss the role of Bianca Stone's images spliced throughout Carson's text and how they function in some

\footnotetext{
${ }^{1}$ Anne Carson mentions Benjamin's “The Task of the Translator” in If Not, Winter: Fragments of Sappho. She also mentions the task of the translator in a letter addressed to Antigone that she read before the Louisiana performance of Antigonick.
} 
ways as translation and in others as a marginal gloss to Carson's theories of translation. The images, organized seemingly haphazardly, show that there is great nuance in the work of collaboration to play with old modes of signification and update them into the new.

Finally, this thesis will discuss a work of translation as a performance alongside the idea that performance can function as philosophy. In essence, Carson's translation collapses the distinctions between what we have come to know as the secondary act of translation and the remote and esoteric thought experiment that is philosophy. By staging her translation and involving critical theorists and audience-goers alike, Carson thrusts critics into the center of the drama while making it impossible for viewers to passively ignore their own complicity in Antigone’s tragedy.

\section{CHAPTER I: LIVING ON BORDER LINES: DERRIDA AND CARSON ON TRANSLATION}

"I think that a text like 'Glas' is neither philosophic nor poetic. It circulates between these two genres, trying meanwhile to produce another text which would be of another genre or without genre... Yet I myself do not read the genre of this body as either philosophic or poetic. This means that if your questions were addressed to the philosopher, I would have to say no. As for me, I talk about the philosopher, but I am not simply a philosopher. I say this even though, from an institutional point of view, I practice the trade of philosophy professor... It is in this strategic context that on occasion I have spoken of philosophy's usefulness in translating or deciphering a certain number of things, such as what goes on in the media, and so on" - Jacques Derrida, The Ear of the Other

"What does philosophy say? Let's imagine that it's possible to ask such a question: What does philosophy say? What does the philosopher say when he is being a philosopher? He 
says: What matters is truth or meaning, and since meaning is before or beyond language, it follows that it is translatable. Meaning has the commanding role, and consequently one must be able to fix its univocality or, in any case, to master its plurivocality." - Jacques Derrida, The Ear of the Other

Critical theory both informs and is informed by Carson's Antigonick so that the mutuality and interchange between the two are almost inextricable. The manuscript ${ }^{2}$ disrupts the prevalent point of view that critical theory and literature proper are separate inquiries, but it also bolsters the conclusion that literature can birth its own approaches and that in their performance or enactment, literary texts become more akin to theory than the work of theory itself. All in all, Carson's Antigonick offers critical readers an important paradox: it is both a text informed by theory, enacting theory, commenting on theory, and creating theory while attempting to function to some capacity in the same way the canonical original did. Through Antigonick, Carson questions the originary status of theory with her characteristic tongue-in-cheek metatextual irony. The overlapping of theory and literature, reference and representation, and irony and Eros leave more than a pastiche and more than a translation in their wake. Antigonick's mission is one of fragmentation, reconfiguration, and endless questioning not unlike Carson's cry to “deflect and disrupt the boredom of storytelling” in order to undo the clichés of translation ("Variations on the Right to Remain Silent” 3). Not unlike Lawrence Venuti's call to translators and translation theorists to go out and introduce "innovative materials and practices into academic institutions,”(69) (Carson, with Antigonick, creates an

\footnotetext{
${ }^{2}$ Referring to Carson's Antigonick as a manuscript is no mistake. In fact, the material appearance of the book with the vellum plated images and handwritten font becomes another way for Carson to collapse time since these elements more closely resemble a medieval manuscript than a book in novel form.
} 
unprecedented amalgam of philosophy and an exploration of the theory that informs translation which inevitably leads the reader back to the question of translation studies as it stands today.

What do I mean by theory? Antigonick itself does a great job of bisecting Continental Theory as a whole and translation theory without explicitly spelling out the latter. Antigone mentions the Structuralists by name, and she invokes the work of Freud and Lacan on the subconscious and unconscious when she questions whether she could be so "completely conscious of being unconscious that [I] am guilty of my own repression” (Sophocles and Carson 33). Carson even deftly reminds us of Hegel’s dialectics when Antigone cries out, "Hegel says I am wrong. . . and right to be wrong” (Sophocles and Carson 33). This statement serves as invitation to readings through the lenses of these theorists, certainly, but it may very well be that the contemporary theorist Carson does not bother to mention, Jacques Derrida, is actually the best fit for a reading of the text. Embedded in the text is a singular obsession with Derrida ${ }^{3}$ through the character of Antigone although the character never actually names him. Her fixation is present through the constant need to undermine binarism imbedded throughout the text with her mentions of the excess between life and death, woman and man, image and text, and translation and performance. With a mention to these apparent opposites, Carson plunges towards the fact that even the Antigone she has translated in Antigonick is herself

\footnotetext{
${ }^{3}$ Carson creates connections to Derrida in her book Men in the Off Hours through various poems where she addresses his deconstructive work.
} 
a "strange in between thing" (Sophocles and Carson 36), juggling many opposing positions at once.

This chapter aims to unpack Derrida's ideas about translation alongside those of contemporary translation scholars in order to underscore the interrogative interpretations and arguments expressed about translation in Anne Carson's Antigonick. Subsequently, this thesis will attempt to lay out Carson's singular obsession with translation studies and her faithful production of texts that, like Antigonick, consistently challenge the role of translator and translations. Her unique "translation project[s]" (Venuti 257) exemplify the academic marginality of translation and draw attention to the surrounding cynicism towards the field and open up conversation towards a rethinking of the institutional status of translation as a field. First, this chapter will discuss Derrida's ideas of relevance, living on, proper names, violence, and equity as they relate to translation. Meanwhile, the chapter will pinpoint instances where Carson seems to showcase Derrida's theories in her text as well as moments where she undoes expectations about the end result of translation in order that she might bring Antigone into the present moment of translation studies (Derrida “What is a Relevant Translation?” 226).

Relevance in translation hearkens back to the seminal work by Walter Benjamin, "The Task of the Translator.” In this essay, Benjamin attempts to conceive of translation as an art form and finds that the relevance of translation is in showing the relationship of languages to each other - a task that should not concern itself with the meaning of an original author. Derrida picks up on this conclusion and posits that relevant translations should always attempt to be clear in expression but that they are always plagued by the 
impossibility inherent in this task. Carson herself also addressed Benjamin's task of the translator at the first performance of Antigonick, where, true to the prescience of her characters, she seems to anticipate most of the criticism that would soon be launched her way. It was at this time that Carson brought herself to talk about translation in direct relation to her own works, and she does this in an open letter to Antigone, claiming that "the task of the translator" in a work like Antigone is "to forbid that [she] should ever lose [her] screams” (“Anne Carson: Performing Antigonick” 5:42-5:45). Carson adds a human dimension to Antigone by addressing her directly in the format of a letter, while simultaneously the format works to create a bond of familiarity that gives her credibility. In this letter, Carson sets out to fulfill an oath with an open challenge to the translations or adaptations that may have come before her, those that missed the "relevance" of Antigone and that have imposed themselves as true translations or as carriers of word or message with ideals of false transparency.

American critics often overlook Derrida's role in the shift between the "emphasis in Translation Studies as one from equivalence to difference” (Chattopadhyay 1) or, in other words, the shift between a demand for economic equality in translated works and the emphasis that Derrida places on the many perceivable iterations of meaning that are conjured through the use of one word. In his most famous talk about translation titled “What is a Relevant Translation?”, Derrida addressed a room full of translators with an apology: to the translators he says that he recognizes the "insolvency before translation," or the thankless task of translating, and credits translators with the singular achievement of being "the only ones who know how to read and write" (175). He used this apology to 
highlight the multiplicity of his own mother tongue, French. Derrida emphasizes the word "merci" which in French means "thank you." Yet the word merci can, in the same breath, also call forth the word "mercy" or "pardon," too. His talk functions as both apology and expression of gratitude.

In this talk, Derrida also seems to recognize the subordinate position of translation to other fields of literary inquiry and rails against what Lawrence Venuti (Derrida’s own translator and a translation studies scholar in his own right) calls the "double marginalization” (238) of translation studies, or the ways in which the field has been stunted by both theoretical and linguistic approaches that are too concerned with equivalence. Consequently, Derrida dismisses the obsessive emphasis on grammar and lexicon, opting instead for the importance of what is revealed when another's language licks at words like flames and illuminates the multiplicity of meaning - the Babel of languages hidden beneath the surface. Instead of folding languages over and onto each other to create a two-dimensional figure, Derrida invents the stereoscopy of language, one that, like the superimposition of the images in Antigonick serves to add dimensions of meaning that help us discern the poststructuralist implications of the failure of language to represent. Since the "failing of the sign is in itself a sign" (Sophocles and Carson 77), translation serves Derrida's deconstructive agenda faithfully, given that translation always already evokes both lack and multiplicity and, as a result of postmodernism, implies that language fails to signify any one thing. The translator no longer tries to find the direct mimesis or correlation amongst words from differing languages because words already contain the variations and traces of these other languages. Derrida posits that the 
culmination of all "reading-writing" is the "summons to translation" (175); in other words, the creation of a text or a manuscript automatically foreshadows translation and the inevitable failure of translation. In a Beckettian move, the translator must try again, fail again, and find some consolation in the idea of failing better next time.

What is it that undoes this ideal of seamless, clear translation? For Derrida it is the polysemy of language, or the idea that languages are already never only one. Whenever a homonymic or homophonic effect occurs in translation across languages, this idea of oneness is already disrupted. Derrida uses the word "relevance" to illustrate his dismissal of the excessive worship of this idealistic conception of language. Relevance is a word open to French and English as the adjective marked by the meaning of "relever" in French. Now, because translation studies and translation itself emphasizes this kind of semantic transfer that Derrida terms an "economy of language," the text arrives unmediated in its final state - all mark of the translator is gone and in its stead we find this appearance of transparency. A fluent translator well versed in translation would, in carrying out their task, appear to create an untroubled semantic transfer. In sum, this kind of relevant or transparent translation would not appear to be a translation at all. This is not the case with Carson, where from its conception, the text is not striving for this seamlessness or erasure of the border lines.

In her attempt to disrupt cohesive notions of translation, Carson set up the front cover of Antigonick in seemingly contradictory ways: first, by claiming that the work is only a translation and nothing more; then, by splitting the title between the first part, Antigo, and the last part, Nick. In ancient Greek, “Antigone” means something along the 
lines of against birth. As Oedipus' daughter, born through incest, she is well suited for the paradox. Carson drives the point home by opening up her translation as follows:

[Enter Antigone and Ismene] Antigone: We begin in the dark and birth is the death of us Ismene: Who said that Antigone: Hegel Ismene: Sounds more like Beckett Antigone: He was paraphrasing Hegel

(Sophocles and Carson 3)

This could very well be a paraphrasing of Hegel or Beckett, a moment of catachresis, or just a clever way of pointing out Antigone’s impending doom with a phrase that her name already implies. In fact, “Antigone”, the name, already sounds a lot like agony and the agony of translation is certainly present in this image. In line with Derrida's argument about the polysemy of language, the morpheme Antigo evokes its Portuguese counterpart that means ancient, yet it also implies the lesser-known Antigo of the Chippewa Indians which stands for evergreen (Stennett 37). Is not Antigone both ancient and evergreen? Does she not travel from her roots in our ancient past to remain an indelibly enigmatic figure because of her youthful demise and defiant plight against the tyranny of Kreon’s unbreakable edict? To remind us of this fact, Carson makes it a point to continuously reference Antigone’s legacy throughout Antigonick by conjuring names like Brecht, Hegel, and Beckett directly from the mouth of Antigone herself. All of these figures, prominent in philosophy and literature from separate schools of thought, share a common interest in translation and in the figure of Antigone as she's been translated, reworked, and interpreted. 
Antigone's anachronisms in Carson's manuscript project themselves forward in time to give us Nick, a silent part in the play whose sole direction is to measure time and space and who makes his first appearance on the cover. He is both a figure and a cut. If you nick the title, you arrive at the image that separates both words: a picture of a ravine and a lone, amorphous figure that walks between the two jagged cliff edges like the translator, straddling one language and the other. This figure reminds us that the "border lines between which translation has been performed, has, over time, always been conceptualized [as] torn between some pure untranslatability, based on an impossible trans-lation of the letter of the text, and some exhaustive translatability, based on a complete rendering of the meaning of the text” (Ertel 6). By showing the reader the opposite borders of translation, Carson enacts the conceptualization of translation as that which exists and is birthed in between borders. Are they the borders between birth and death, cut short by darkness and tragedy, or are they the borders between culture and language which only translation can attempt to surmount? The cover page alone nullifies any idea of univocality and positions the text as some strange new hybrid form, a form that physically embodies translation.

Further on in "What is a Relevant Translation?”, Derrida claims that the highest form or notion of translation is the idea of living on or "infinite history" inherent in the task of translation. Derrida asserts that a triumphant translation is "neither the life or the death of the text, only already it's living on, its life after life, its life after death” (Ertel 9). The idea here is that every time a work is translated, it is extended past its own lifespan per se. The newly translated text continues the life and influence of the canonical work in 
another language and through another culture. Works that can be translated, or that have all of the qualities of translatability, seem to gain with them an otherwise untenable immortality. The task of the translator is, for Derrida, elevated to one of near God-like proportions where translators are charged with the singular responsibility of giving the source text a way to remain in public consciousness indefinitely. In a way, this new translated iteration is asked to watch over the "maturing process of the original language and the birth pangs of its own” (Ertel 10).

The conception and inclusion of Nick as a character in Antigonick makes a different kind of commentary about time and the historical relevance of translations for Carson. There's a fixity to time that comes undone in Antigonick and allows the reader to see as well as read the collapsing of time through Antigone's self-conscious monologues. It is also this crowning achievement that makes time a focus of Carson's own translation. By directing so much attention on past analysis of Antigone, Carson clears the way for a new relevance. She does so by painstakingly describing Antigone’s distress at the hands of Lacan, Freud, and Hegel. That they tried and failed to rationalize her actions through whatever means were available at the time only comments on the stunted quality of our limited horizon of being. Since they were married to one place and one time, it stands to reason that translators and interpreters must update the myth to suit the times, or rework the translation to make it appropriate for the moment.

For example, let's take the reference to Bertolt Brecht's 1948 adaptation in which Antigone is plunged into the war torn world of mid-WWII Germany. Based off of Holderlein's translation of the original, Brecht's version re-purposed the text to suit the 
political and historical climate. In his version, Polyneices dies a traitor and deserter of the German army and the play is ruled over by a tyrannical Nazi figure. Consequently, the chorus in Antigonick reminds Antigone that in Brecht's adaptation, she clumsily stumbled about on stage with "a door strapped to [her] back” (Sophocles and Carson 63). Immediately, Antigone replies that she does not wish to talk about him (Brecht) "or him, or him" (Sophocles and Carson 63). The word him in the text is written in bold, repeated three times, and finally, highlighted in red, which adds gravity and emphasis to the gender of the translators and directors under scrutiny and lends Antigone a dissenting voice in the execution of her image. Highlighting certain words in red bisects two pertinent points for Carson's own understanding of translation through Sophoclean tragedy. In "Variations on the Right to Remain Silent," Carson seems fixated on Holderlein's translation of Antigone, on the blind literalism that made him a laughingstock to the likes of Goethe and Schiller and which eventually drove him to a madhouse. All of this she states without mentioning the fact that contrary to Holderlein's situation, Brecht’s adaptation was a resounding success. Carson, more than anyone, seems to understand the disfigurement of language and translation of which Holderlein was accused is just a consequence of reaching for clarity.

She adds that it was Holderlein's literalism which translated the first line directed by Ismene to Antigone as "you seem to color a red word, to dye your words red" (Sophocles and Carson 6) instead of the original Greek word "kalchainein.” The Greek "kalchainein" is figurative and means, "to search for the purplefish" ("Variations on the Right to Remain Silent,” Carson 6). The purplefish was a creature that the Greeks ground 
up to produce ancient purple and red dyes, but it is also used as a figure of speech that means something akin to "growing dark in the mind" ("Variations on the Right to Remain Silent,” Carson 6). Obviously, Carson intends to emphasize certain words by dying them in red, but in this moment, her evocation of Hoderlein also expresses a certain kinship with his madness. One can hardly ignore that "him" is clearly gendered, and it stands to reason that part of the emphasis on the word comes from the purely maledominated discourse that has surrounded Antigone for much of her existence. Part of Carson's plight is based on the logic of attempting to arrive at an understanding of a female character when this same character has often been interpreted through and by men ${ }^{4}$. The second result of the emphatic bolding of the word "him" is the production of Antigone's tone, which implies from her very own mouth that the interpretations/translations/adaptations in all of their many previous iterations do not and have not conveyed the timeliness of this new interpretation, that they have definitively passed out of relevance.

Carson's relevance thus arrives in those particular moments where she sets out to undo this eroticized and fetishized model of Antigone. For this, Carson employs caustic irony. Take, for example, the consistent mention of Kreon as the rower of a powerboat. George Steiner ${ }^{5}$, a seminal theorist in translation studies and an Antigone scholar, calls

${ }^{4}$ I do not mean to say that Antigone has only ever been interpreted by men, but that her history is one where figures of great importance who have worked with Sophocles' Antigone - either in the realm of philosophy, translation, or theater - have more often than not been male.

${ }^{5}$ George Steiner is a polarizing and heavily circulated writer among Translation Studies scholars as a result of his book After Babel, published in 1975. Steiner's groundbreaking text posits that all human communication is a means of translation. Since the act of 
this addition a mere "vulgarity" in contrast to his own reverence of this "most adult, unsparingly formal, and radiant of masterpieces” (Steiner 7). Steiner's prostrate worship of Antigone as the apex of Western tragedy is at the very root of the paralyzing (and often male) objectification that Carson combats with irony ${ }^{6}$. It is Steiner's inability to recognize Carson as authoritative in her role as translator that is key to Carson's own message.

In contrast to Steiner, Venuti argues that this gripe against visible change in a text is a new and modern phenomenon that places far too much emphasis on the word, namely the idea that translators are asked to be faithful to a quantitative approach to texts in translation where they attempt to exchange one word by one word. An attempt to translate in the strict, traditional, and dominant way will inevitably come to an impasse. To break away from this philosophy of the word, translation can look to Cicero, who freed the act from this obligation by opening the door to a translation of the senses, one that functions by expressing “not word by word, but sense by sense” (Venuti 180). It

listening is a form of interpretation, it stands to reason that all speech acts, whether within a language or across a language, are translative acts. Feminist translation studies critics often attack Steiner for his use of gendered words to describe translation as well as his fetishization of the text as something to be "penetrated, embodied, and restituted" (Bai 2). Steiner is also credited with having written Antigones: How the Antigone Legend Has Endured in Western Image and Thought first published in 1984. His reaction to Antigonick makes him the posterchild of Carson's plight within translation communities.

${ }^{6}$ The brand of irony is here defined by John Vignaux Smyth as a term intimately linked to the erotic. He connects a tradition of satire with the postmodern by claiming that irony can be both a misdirection that unmasks your opponent in argument and a disruption that "inhabits the gaps between female and male, philosophy and literature, cognition and esthetics, source and imitation, play and work, eros and death” (Smyth 98). This definition continues the playfulness of eroticism and the aim of deconstruction while highlighting Carson's own agenda in Eros: The Bittersweet. 
seems that the only way to overcome this obstacle is to triumph with more - to do away with the notion of a word for a word and to bend the structures of language so that the promise of translatability exceeds them. Take, for example, Carson's only major addition to Antigone’s language, which she cannot claim is merely a translation since it technically exceeds that equity for which Derrida asks her to strive. Her addition occurs on the page that marks the moment where Tireisias, having exhausted his speech, finally forces Kreon to reconsider his actions and sets off to free Antigone from her punishment. This moment, where in Sophocles' original everyone steps off stage towards their action, becomes a written choral ode to time. Carson writes her stage directions as "Kreon rushes out. All the guards rush out. Hang by the neck until:___ (Sophocles and Carson 80). After the colon, Carson includes a blank space that one can take to mean the decree has been acted out in which case Antigone and Haimon are both off stage somewhere, hanging. The word "the" is written to look like die and like thy at the same time, thus standing in as a palimpsest of plurivocality. Meanwhile, in this moment, Carson's chorus proclaims that everyone is "still all right” (Sophocles and Carson 81). At that very moment, in a play enacted in real time, everyone is still just fine. The tragedy of translation has not come to its completion and plunged everyone into darkness. Carson’s addition to Sophocles' text is a way of conveying with absolute resolve the importance of the temporal aspects of the play and of Greek tragedy in general.

The offensive inclusion of Kreon's powerboat that so angered and derailed Steiner in his first taste of Carson's translation can easily be seen as a counterpoint to ideas of translative excess. To begin with, ships and ship imagery are not a significant 
enough departure from the original Greek. Translations that claim a verbatim semiotic transference from the Greek to English include a moment when Ismene expresses a desire to be Antigone's "shipmate in suffering” (Sophocles and Woodruff 65). Aside from the powerboat being an obvious play on words, meant to invoke Kreon’s status as an iron fisted ruler drunk on his own power (but pathetically driving at this fact with a tiny engine-powered boat), this association creates a domino effect that reveals the multiple possible interpretations that present themselves when the words are tied throughout the whole text. In another scene, as Kreon rattles off a list of nouns he enjoys using, he comes back to this idea of a vessel with the term "ship of state," a term that comes directly out of Plato's Republic and was coined to describe the most efficient form of government ruled over by one ship’s captain or navigator who is well versed in philosophy. Plato concludes at the end of the Republic that the best kinds of men to rule over government are philosopher-kings because they are most attuned to the needs of the people since have proved their true love of knowledge. As it stands, this moment in the text when Kreon invokes the Republic is small in comparison to other textual instances of irony, but it is distinct for its subtle foreshadowing of the last line in Antigonick: "Wisdom better get some even if too late" (Sophocles and Carson 101). Potentially, this line can be read as the kind of wisdom that could avoid those fatal mistakes that doom every character in the play. Wisdom, a term that distinguishes itself from knowledge by being that which we acquire from experience, is the finely tuned point of the entire play. If Kreon’s experiences are what should lead him towards wisdom - potentially making him a wise enough ruler - then this only serves to reinforce the inevitability of the tragedy in the text. Kreon must experience the moments when Haimon, Euridike, and 
Antigone die to be able to understand with some certainty his role in the choices that led to tragedy. It is that moment of understanding that generates the feeling we know as the nagging "what if..." that can only come through the perfect, unobstructed moment of hindsight. It is this experiential wisdom that Carson drives at, but it is not foreign to the original text, which ends on a similar note as the chorus announces that one learns, in old age, to be wise (Sophocles and Woodruff 123). The updated version of the line offered us by Carson is really just a new intimation of the Greek original, a successful straddling of two cultural boundaries.

If translation must make a concentrated attempt to steep itself in two cultures (in this case, the Anglophone and the Greek), then it might strike the reader as strange to see so many philosophical figures and colloquialisms pop up in Carson's text. These proper names, peppered throughout Antigonick, manifest themselves in both direct references to Hegel, Brecht, and Beckett and indirect references to Heidegger, Derrida, and the Structuralist movement. They emerge as parts of the dialogue and are spliced into the places where we as readers know other words in Greek must be. Still, the choice creates several thought experiments that do, in fact, complement the tragedy while imposing an even more difficult translative problem onto the text: that of proper names. Derrida uses this idea of proper names as an example of the untranslatable.

According to Derrida, the idea of proper names can be traced back to the biblical story of Shem and his descendants, who set out to build the tower of Babel so that they could touch the heavenly kingdom of God. The idea was such an affront that God descended upon the Shems and pronounced his own name - a name that has been 
translated as Babel, or confusion in Hebrew. The double bind of translation was thus presented to the Shems as the call both to translate the name into their own words and not to translate the name for the sake of piety or reverence. These proper names in translation stand for symbols of property, of belonging to just one person, and as such call out in the same way God did to have the power of the proper name translated along with its' claims to singularity (yet another double bind). Take, for example, the common French name Pierre. The word, were it not capitalized, could very easily be translated into English as rock, but it becomes impossible to translate it that way when it means the singular name of one person existing right in the very moment who is a composite of many things at once. The Nick of Time is a place where Carson creates this impossible impasse. If someone were to undertake the task of translating Antigonick into yet another language, they would find themselves in a predicament when they came around to translating Nick who is a cut, a space, and the proper name of a real character walking around the stage measuring. Because he is all of these things at once, person and object, he is an untranslatable but essential quality of the play. Furthermore, one cannot ignore the infinity of the history to the word nick as well, the very "insaturable context" of the word to begin with, that in some cases adduces violent action with a slice (Derrida "Monolingualism of the Other" 10).

Derrida makes the connection between translation and violence in his talk about the relevance of translation because translation is the wresting of words from one language to attempt to fit another. Akin to this process of cultural domestication is the whittling down of the original language to fit one's own language. The metaphorical 
connection between translation and an undercurrent of violence is not lost on Carson who did attempt (it seems only one other time) in 2008 to write precisely about the very issue of translation in an article titled "Variations on the Right to Remain Silent." In this article, Carson lays out both a figurative framework for translation and a practical one with multiple examples of how translation "paints the scream, not the horror" (Carson 5). I am well aware that that is in itself a metaphor. So is Carson, which is why she later attempts to unpack the image for us by using the paintings of Francis Bacon to juxtapose the sensationalism that surrounded his paintings and what Bacon considered his responsibility to paint the interiority of the figures that he copies over - to render the scream that is already there, trapped but evident in the energy that emanates from the subjects of the paintings.

For Carson, this violence takes the shape of portmanteaus or compound words invented in order to render the nuance of the original Greek (similar to the dilemma presented in Eros: The Bittersweet at the start of this thesis). One such instance happens when Kreon's guard tells the story of how he discovered Antigone burying Polyneices. The guard claims that, as he watched her from a distance, "she was the child in her birdgrief the bird in her childreftgravecry” (Sophocles and Carson 25). The nouns and verbs in this sentence are pushed together to create hybridized manifestations of new language, transforming all these words into nouns, neither English nor Greek. Kreon likes nouns, his guard gives him nouns. In comparison to other translations, Carson is playing on the image of the birds that defile Polyneices’ dead body. 
Still, the most interesting approach may not be that far from Sophocles' own method of writing, as cited by Albert Rijksbaron et al. They claim that Sophoclean language includes many instances of compound adjectives, nouns, and verbs (Sophocles and the Greek Language: Aspects of Diction, Syntax and Pragmatics 55). I'd argue that Carson fights excess as much as she seems to indulge in it. In fact, Carson's translation is parsimonious with words, cutting down on the amount of them and doing away with much of what English convention would call “connective tissue” amongst sentences. The choice to leave out all punctuation is also a clever way of staging the material condition of the original Greek scrolls, which would not have included punctuation either and would have been written in the scriptura continua style. The violent act, for Carson, takes a surprising reversal. Because she does not attempt to force the source language into the tight fit of our own, she inverts the violence towards the receiving language and makes violence of words, snipping them apart and piecing them back together so that they more accurately color the correct meaning. That translation has "violence as its essence" ("Variations on the Right to Remain Silent" 4) is something that Carson and Derrida can both agree on; that it doesn't only see itself enacted upon the host language is the source of their difference.

As a lifelong translator and scholar, Carson's concerns about the state of translation studies and the crucial moment of translation are clearly remarked upon in Antigonick in ways that exceed even Derrida's own assertions. Evidently, Carson is not just a simple apostle of Derrida's ideas - disseminating them without altering them. Instead of just writing about translation, Carson attempts to enact theory through 
Antigonick, to comment upon ideas, and to expand their scope. But make no mistake about the end result, which is a faithful and thought-provoking translation and which bears the responsibility of being thought of as a translation. Clearly, the fact that translation is bound to language is no mistake for Carson, who is mired in the paradox of this situation. To accept that it is only through words that one can communicate translation would limit the study altogether and would ignore those elements that stand outside of that reasoning. Thus, for example, Carson incorporates Stone's images into the fabric of Antigonick. The next chapter views these images as marginalia that directly gloss Carson’s ideas about translation and translation studies while expertly proffering thematic interpretations of Antigone. 


\section{CHAPTER II: PAINTING THE SCREAM: STONE, CARSON AND IMAGES IN TRANSLATION}

When language fails to clarify, the reader must look towards other ways of meaning-making. To this end, the perceived universality of images becomes a fruitful avenue for generating understanding. From storybooks to instruction manuals, we have added images to words so that meaning becomes intelligible, and usually, our first lessons with language involve the transference from the realm of the visual to the linguistic. The focal point of Antigonick and its greatest departure from Sophocles may be the inclusion of Bianca Stone’s vellum plates. Even if every word could be read as a direct translation of the source text (which I hesitate to endorse even briefly), where do Stone's images fit? If they relate to the text at all, Stone's illustrations must be explained in conjunction with Carson's claims of direct translation. Translation studies and Derrida both wrestle with the generally recognized rule that translation must always take place between one word and another. Conceptually, translation occurs between a representation of a word in one language and the transference of that representation into another language, but still, we have generated this notion of a word for a word. The act of translating should be open to divergent means of interpretation and representation, but scholars have long resisted the implications of this kind of open and creative forum for fear of tainting or diluting a quality of the essential and faithful translation. In "Des Tours

De Babel,” Derrida speaks directly to the work of linguists like Roman Jakobson when he questions the latter's neat tripartite division of translation studies into that which operates within the same language, that which operates across languages, and that which is delivered through nonlinguistic means (Derrida 8). According to Derrida, Jakobson 
terms this kind of translation an "intersemiotic translation or transmutation" ("Des Tours De Babel” 8), wherein linguistic signs are interpreted by or through a system of nonlinguistic signs, but Jakobson is quick to dismiss this transfer as improper or as less desirable than the first two. Derrida sees Jakobson as imposing a kind of linguistic imperialism, and he spends a great deal of time listing the kinds of writing that may benefit from divergent forms of translation, such as metaphors, figures of speech, and poetic language.

Antigonick, like most of Carson's projects, is involved in the act of endless deferral and jouissance ${ }^{7}$. In this case, like Francis Bacon, or Carson before her, Bianca Stone attempts to paint the energy that surrounds a figure and portray it via images so that what comes across is not the figure itself, but some version of the chaos of momentary anxieties, feelings, and that metaphysical silence Carson envisions when arriving at a word that does not want to be rendered translatable. As Carson writes in "Variations on the Right to Remain Silent," Stone "paint[s] the scream not the horror" (5). In a sense, Stone's drawings are an attempt at translation - a translation of the senses. Perhaps, The drawings appear to be functioning in the same way that marginalia does in medieval manuscripts, "combining traditional motifs in new and challenging ways" (Camille 15) and managing to reinterpret a text that may seem fixed or finalized. Instead of the one-toone relationship envisioned by Jakobson or even Derrida, Stone's images seem to gloss key concepts in the text that clarify theme and methodology. In essence, the images

\footnotetext{
${ }^{7}$ Barthes's jouissance is already at a translative impasse. It represents the act of coming, of sexual bliss, of joyous excess, and it corresponds to Derrida's relevance because it is that which exists.
} 
function as annotations since the drawings consistently and purposely fail to represent narrative. Instead, I posit that the images attempt to straddle the line between a thematic representation of the book and the paradoxes of translation. Stone accomplishes this through a semiotic pastiche of images collected from the Sophoclean original juxtaposed with elements of Carson's previous texts. The images are the result of what I imagine as a conversation between the translator and the illustrator, which we receive in the form of a collaborative pastiche of both image and text whose materiality offers up a space for the conversation to continue.

Materially, the book juggles three separate medias: the written, the representative/imagistic, and the performative. The triangulated model Carson articulates is a conspicuous feature of a number of her works, not least of all Antigonick, whose very materiality brings to a head the way images and text relate and yet at the same time never quite conflate into one clear narrative or meaning. Carson's theory of desire builds its intellectual momentum from an explanation of a fragment of Sappho's verses and illuminates a "poetics of lack," one that draws out the relationship between the beloved, the lover, and the gaps in perception as that which both connects and separates. The geometry of this theory can be applied in any number of relationships: that of lover and beloved, reader and writer, translator and author, and in the case of Antigonick, it can be seen to elucidate the shaky relationship between image and text. In Eros: The Bittersweet, Carson makes clear that the shift between the written and spoken word marked a moment when Greek culture was more finely attuned to edges - or what separates one from what they desire. The cataclysmic shift towards triangulated desire began with changes in 
Athenian cultural and philosophical life transforming what was once a culture reliant on the immediacy of the spoken word into one that emphasized the longevity of written language. The moment of desire, then, is never in the consummatory act, but in the reaching for the object, and the object of desire can range from the satisfaction of arriving at knowledge or the comfort of obtaining a beloved object long beheld from afar. But it always evolves in paradox and instability. Once the loved object has been attained, desire ceases. Reminiscent of Derrida's work on Border Lines, Carson's theory of Eros is one that enacts its own reaching for understanding. In the case of Antigonick, it is both an understanding of translation and of the Antigone myth, and it happens through yet another triangulated relationship between translator, author, and illustrator.

The superimposition of the images drawn by Bianca Stone and the text creates the very sense of stereoscopy - or illusion of depth - that Carson describes in Eros: The Bittersweet. For Carson, the act of reading creates this moment where simultaneous processes meet but do not quite align:

Exegesis mars and disrupts pure absorption in the narrative. The narrative insists on distracting your attention from exegesis. Yet your mind is unwilling to let go of either level of activity, and remains arrested at a point of stereoscopy between the two. They compose one meaning. The novelist who constructs this moment of emotional and cognitive interception is making love, and you are the object of his wooing. (58)

As Carson affirms, the act of holding two things in the mind at any one time destroys any pure absorption and keeps the reader aware of their position outside of the text. The 
mental exercise lies in creating a three-dimensional whole out of two fragments or through an awareness of fragmentation. Through Antigonick Carson is attempting to woo us with the interpolation of the image and the cognitive aspects of the text. Carson mentions a quest for wholeness, but this wholeness comes through stereoscopy or the idea of holding the image and the text in a simultaneous and paradoxical stasis for just a moment.

It is Tireisias, the blind prophet, who says that the "failing of the sign is in itself a sign” (77) in Carson's translation. Some may recognize this statement as part of the larger conversation about philosophy in Carson's work - the result of discourse surrounding structuralism that reached its culmination in literary criticism with Roland Barthes, who connected semiotics (the study of signs) back to literature and popular culture. The sign as it is being used in Tireisias' prophecy could refer to Antigone’s impending tragedy and his desire to spell it out but also to the images themselves whose sole purpose is to cement an already crumbling relationship between signifier and signified $^{8}$. Now, part of the problem as Tireisias sees it is the idea of representation: that

${ }^{8}$ As Richard Kearney explains, Ferdinand Saussure made the distinction between signified and signifier and directed philosophy towards the idea of thinking of language as a regulated system of signifying relations. The only determinant between particular words is their relationship and opposition to each other. In essence, words must relate to each other in culturally agreed upon ways in order that they might signify anything at all. There is no reason why we as humans agree to call a cat 'cat', no phonetic reason that leads us to this word above any other except that the meaning of the word is agreed upon. There is no 'cat-ness' or essence of cat that makes the word most appropriate. We only know that a cat is a cat because it is not a dog or any other creature. Semiology, which also includes Roland Barthes' later work fell under the branch of Structuralism. Structuralists believed that the world was governed by a system of signs and that the point of the philosopher was to uncover this system of signs. The constraints of structuralism make the philosophy one that fell prey to dichotomy and binaries: a thing is 
any one sign can at any point represent multiple things. At another point in the translation, Tireisias accuses Kreon of making a "Structuralist mistake with life and death” (67), which means that Kreon is too caught up with the representation of a system of signs. He wants the dead to represent the dead and the living to be the living, and his affinity for this binary is what dooms his nuclear and extended family. Tireisias would know otherwise; he is not only the prophet who was never proved wrong, but himself a strange inbetween thing, castrated and blind, but endowed with power and foresight. The connection to structuralism is obvious, since structuralists like Barthes believed that all phenomena and occurrences could be traced back to a larger system of signs by which they are governed. Should it strike the reader as odd that Tireisias brings up Structuralism to prove his point? Only if one forget that his character has the ability to see into the future. Time, which is such a central component to the points Carson makes about the play itself, is present throughout all of the talk in the work. Aside from the inclusion of Nick, the character in the play who stands around measuring things and represents the nick of time when action is pertinent and necessary, there is also Antigone who constantly expresses the binding paradox of tragedy by referring to her status as "[lying] in a bed on the river of death while [she] is still alive” (Sophocles and Carson 63). The fact that neither Hegel nor the Structuralists can offer up one unified idea of Antigone gestures at the sign itself and only serves Carson's purpose, which is the reading of this

either this or that. Poststructuralists in the vein of Derrida contended that signs can represent many things at the same time and that the exploration of this multiplicity is fruitful for academic inquiry. 
text as it stands: as a translation created by the bisection of time and place, of image and text.

Repetition, in this case of certain objects or concepts, turns out to be the only clue in generating a theory of the images. By repeating certain figures, Stone begins the process of transforming the seemingly nonsensical into patterns that accrue significance. In other words, Stone creates literary symbols or motifs out of her drawings. It is only by grouping the objects portrayed in Stone's images that one can see she revisits shapes and ideas often. Amongst the figures revisited are spools of thread, a horse, human bodies with cinder block heads, empty rooms, doors, and staircases. Spools of thread show up at least four times amongst the thirty or so images (see Appendix). At one point, the spool ties up cutlery that is floating away - a family much like Antigone’s that just cannot seem to stick together. Ancient Greek symbolism is present through the spools as well and is reminiscent of an image of the three fates spinning, cutting, and measuring the fate of mortals with their spools of thread, much like the dramatist or Nick - our in-house measurer of things. The spools themselves also seem to tie up the book thematically and imply with this action the careful construction of a singular vision as well as the sense of interconnectedness within the book.

The challenge with the images, it seems, is offering up a conclusive understanding of them as aid or hindrance to translation. Since they avoid most classification, any attempt at unraveling them must be done through the thematic. The choice of vellum as the visual medium is important since it allows for the images to lay over the text so that they often conceal words while revealing others. This effect could be called a moment of 
palimpsest, yet I hesitate to call it that since the words beneath are not erased in any permanent way. It is only a matter of flipping the page for the reader to recover what was seemingly lost. In addition to the vellum pages spliced between pages of the text, the verso page of the manuscript is always and conspicuously left blank. Throughout the book, these opposite pages have what looks to be the beginning of a black square (often just a corner or one side) so that by flipping the image we invert it and set it within the frame. Subsequently, we can behold the image and the text at the same time. Readers are meant to look for meaning within the images, although meaning is not tempted to arrive such is the plight of desire.

Take, for example, Stone's images of dinner scenes (see Images 21, 14) that combine the strikingly common with elements of pure fantasy, such as a horse in midmovement, paralyzed at the table, or plates served with heaps of dead fish (see Images $30,16)$. The horse, in all of its appearances, seems to be paralyzed mid-movement, its hooves usually flung up in the air, almost as if someone had pressed the pause button in the middle of its protest. Part of what connects the image of the horse to Antigone are those places where, in the original, Kreon compares the taming of Antigone's will to the image of a horse being yoked by its master. Obviously, Kreon wishes to subdue this onewoman rebellion and fails in pivotal ways, dooming himself and others around him. At the same time, in the chorus' famous Ode to Man there is one reference to the ingenious advances of men who have managed to "[take] down the shaggy necked horses and mountain bulls” (Woodruff 347-52) but who cannot find a way to elude death. Antigone is unique here since she does not want to avoid death. Even if she did, the point of 
tragedy is that the characters walk willingly or not to their own deaths. Certain always of their fate, they walk like Antigone, between life and death in the Nick of time. For Carson, time is created and extended within a text by the spaces between things, as she claims in "Variations on the Right to Remain Silent" (Carson 11). Stone's horses are sometimes tied by the same red string that pops up as part of other illustrations. Time plays a crucial part in these images, through the appearance of motion arrested. At one point, the horse is bound by the red string on the page before Tireisias' introduction. The horse rests between the only two lines of text on the following page that announce the prophet's arrival. If the horse represents Antigone, then this horse waits in its bound form either to be released or to perish. Stone's horses always maintain the look of movement as if the frame of a home video had been stopped much like action stops before the decline of tragedy. The red string is evocative of Antigone's limited time - her string has already been cut and arranged by the fates. It is only a matter of reaching the end of the play.

In "Variations on the Right to Remain Silent,” Carson invokes process as an artist's highest achievement. That is, she privileges the journey over the seamless appearance of a finished product. A highlighting of process over product is also the plight of translation studies. The habitual silencing of translators coupled with the difficulty in articulating a process is what creates insurmountable hurdles for translators who, like Francis Bacon in his art, struggle to create a language that will convey with singular purpose the minutiae and deliberation of their many choices. Far from bringing them praise or respect, talk of artistic process becomes cliche and continues to relegate 
translators to their secondary status beneath that of original authors. Luckily, Carson ventures to explain her process as clearly as she possibly can in Nox: "In one sense [translation] is a room I can never leave, perhaps dreadful for that. At the same time, a place composed entirely of entries” (53). As with most things Carson writes, this passage is rife with double meanings. The room is akin to the many rooms we see in Stone's illustrations; in four of the twenty-four images, she has actually painted a room, while most of the other images still contain the mundane props and furnishings of rooms. Doors, rugs, light sockets, furniture, and windowsills are mixed in with statuesque landscapes, like the one on the front cover, as the domestic and the sublime.

Now, if the rooms of Stone's imagining are also the room(s) in which the translator is trapped, then the entries can be understood as both the many singular entries in a dictionary that comprise the translator's lexicon and also as ways of entering or exiting these rooms. Stone's doors are drawn to look both open and closed at the same time. They defy laws of perspective by requiring a closer look, and after looking more closely, they defy laws of logic by standing off their frames or opening against their hinges. For example, in Image 25, two doors stand open in the background. One of these doors seems to lead out into a hallway where there is yet another door waiting to be walked through. These series of doors, open yet closed, gesture to the endless rooms of translation and the endless deferral of Eros. At another point in Nox, Carson reiterates that translation can be seen as a room "where one gropes for a light switch" (Carson 54). Subsequently, overlaid on the one major translative departure of Carson's choral ode to the nick of time is Stone's watercolor painting of a lamp plugged into a wall. Here is the 
moment where the translator shouts, "Eureka!” The discovery lies in the suggestion that, like Venuti and Cicero, a translator must take on the added responsibility of breaking the established rules of translation for the sake of transparency. The choral ode Carson has added invokes the Nick of Time or that moment in the play before Kreon makes the choice to free Antigone from her burial tomb. In this ode, the chorus sings a pious song to time that does not appear in any of the verbatim translation of Antigone that I looked at for this project. It appears to be an original addition by Carson herself. Conceptually, they sing this song as they are "standing in the nick of time." Visually, Carson conveys this when she leaves a finger's width worth of space between the word nick and the declaration that at this moment everyone is still "all fine" (Carson 81) or that the tragedy has not come to its completion. That visual cue is the nick itself, or the moment, the hour, the second before the tragedy unfolds, when one can still imagine that there will be a different outcome. This moment hangs arrested, and the potential choice to break the cyclical nature of tragedy still circulates in the air. Like stereoscopy, the reader stands, waiting for the moment to break with the inevitability. Stone heralds Carson's ancillary ode by indicating the place where the light of translation receives its power or where the moment of translation's brilliance is most apparent.

In addition to images of rooms, Stone paints multiple staircases and ladders that appear to represent the moment of desire Carson wrote about in Eros: The Bittersweet. The staircase in Image 27 is equally as fantastic as all of Stone's other images throughout the work, where feet peek out from the uppermost rung of a set of stairs, placed in the middle of mountainous terrain that looks like the continuation of the front cover's 
landscape. This image covers the only portion of the text where Euridike is present. In it, she has more spoken monologue than in the whole of Sophocles' play. Euridike, like Tireisias and Antigone before her, also challenges the conventions of time and paradox by comparing herself to Virginia Woolf's Mrs. Ramsay in To The Lighthouse, whose death is the result of a parenthesis, of a simple aside while her husband was "the man whose moods tensify” the world of the story (Sophocles and Carson 89). Once more, Carson's irony argues the case of women in literature, reduced to being the footnote of a story and marginalized to a secondary position. Euridike questions Nick in this moment and the words are laddered downwards. If we look through the inlay, the steps of the staircase allow us to see the sinking quality of her speech through the vellum.

I am reminded of Carson's musings about paradox, how paradox can take the shape of reversed stairs. She describes paradox as a "paradox in time as well as in space" (111), similar to Antigone or the horses in Stone's images, but she goes on to compare finding an understanding of a poem to climbing up M.C. Escher-like staircases. Time is essential. We cannot run down the stairs to rewind the time it took to get to the top, in order to arrive at stereoscopy again. Time, irrecoverable and irreversible, is both the “condition of delightfulness and of perishing” (Eros: The Bittersweet, Carson 115). Nathan Proctor sums this moment up when he says:

For Carson, reading is an education in desire. That's why, through the erasing of boundaries, she draws the reader of her criticism, now dizzy, up a staircase not far removed in incompatibility and impossibility from an M.C. Escher drawing. Up to the handrail, the reader then looks down, frozen in time, down through the work, 
down through her self, and into a moment when the work and the self are onewhen the work is the self, the self is the work, and a blank page is created. (18)

Even though I am mostly in agreement with Proctor, I want to stress Carson's own obsession with edges. She celebrates edges and borders for their ability to make visible our own desire for wholeness and, as such, the entire idea behind desire in the first place. Edges are the places where fragmented subjectivity is exposed most vividly to us. The possibility of stereoscopy is a feature of Carson's work, but holding the image together as one cohesive whole is only possible for a split-second before the mind once more acknowledges the two separate elements of depth involved in the play. The edges also acknowledge what is inherent in translation, or the idea that translation forces together two languages and two cultures, which despite their similarities must not ever be one for too long for fear of erasing those boundaries back to some monolithic, monolingual understanding of translation. It is important that we come back to those moments of discovery, whereupon flipping the vellum page, we find that the image has been almost perfectly contained within a darkened half-completed frame. These edges are present in some of the blank pages and become more frequent the further we delve into the book. The images spill out a bit from these hard-set edges like language, like that catastrophic excess that Carson says inhabits the stories of all tragic characters. It is appropriate that these minor additions exist on the blank verso pages since they are indicative of the absurdity of the book's attempt to contain those images that burst out of its edges. That excess is most valuable since it illuminates Carson's earlier argument expressed as the 
desire to stray from cliché by exposing and cultivating excess. The fact that the images cannot be contained or easily boxed in speaks to their ability to spill over and into

Reminiscent of Escher, Stone has added elements of the absurd to her own paintings, where stairs do not lead anywhere or hang without any support on the short ledge before a jagged cliff's edge. Those same images of staircases that echo Escher's engravings are only part of the entire image. If we look again, at the top of the steps is someone's body, but the viewer can only see the bottom half of the figure with its feet sticking straight out. It is not the first time in the image series that disembodied feet/legs appear. In fact, they show up at least two other times throughout the book, and always they are cut off from the body that owns them. The image of feet crops up in the text as well when feet are burned by the fires of wisdom. The act of acquiring wisdom, which was talked about as part of the translated text that is faithful to the Sophoclean original, is once more made present by the images. In this case, think of Carson's aphorism about "hope coming in to tickle your feet" (41) in Antigonick only to end up burning them and especially think of the final line of the play "wisdom better get some even too late” (101), as the difference between Kreon watching and criticizing Oedipus for raining down destruction on his immediate family and the irony of his doing the same through his sheer inability to learn from Oedipus’ mistakes. Kreon must burn his feet in the fire in order to learn, if only too late, what kind of curse lies upon his immediate family a fact that furthers the emphasis on time in the whole of Antigonick. Like the myth of Shem and his descendants that Derrida emphasizes in "Des Tours Des Babel”, genealogical curses were 
the first obstacle presented in the quest to disentangle the confusion of translation and similarly, they parallel the first of Kreon's many impasses.

In sum, Stone's images in Carson's translation prove to be elements of stereoscopy deeply tied to both thematic translation of feeling or sensation as it is portrayed in Antigone and as marginalia that comments on the mental preoccupations of a translator. The last chapter in this thesis explores translation as a performance that enacts, comments, and interprets words in real time. It also discusses the grander implications behind the relationship between performance and philosophy. 


\section{CHAPTER III: SEE OUR LIVES ON STAGE: PERFORMANCE AS TRANSLATION, TRANSLATION AS PHILOSOPHY}

Alex Deuben: Do you think about how the play could be performed, or at least how the language could be spoken as opposed to read when you translate a play?

Anne Carson: Yes, every minute.

-Alex Deuben’s Interview with Anne Carson about Antigonick July 29, 2012

Multiple stagings of Antigonick took place directly following the publication in 2012 of the text and all the way until 2014, when most of the attention waned. On February 22, 2013, Antigonick was staged for an audience at New York University (NYU). Carson herself played the role of the chorus, while famed philosopher and gender theorist Judith Butler stepped into the role of Kreon. No record of this performance remains, but luckily, Butler went on to reprise her role as Kreon in the 2014 version of Antigonick performed for the Sorbonne, which was recorded and (thankfully) exists online. Ben Hjorth put this second staging together for the second annual philoperformance conference hosted by the Sorbonne. Butler was not the only critical theorist and academic powerhouse to tackle this performance; the stage also included such figures of contemporary criticism as Avital Ronell and Elisabeth Angel Perez ${ }^{9}$ as well, performing Antigonick alongside an audience of students who were asked to read the chorus' parts as they were projected above the stage.

\footnotetext{
${ }^{9}$ Perez has written extensively about Beckett and performance theory.
} 
It still is not clear who chose Antigonick to inaugurate this moment in philoperformance, but the portmanteau is apt in its incisiveness. It calls to mind the singular purpose of the academic study of art in its performance, which is to enact philosophy and to engage others in that activity, so that understanding can enter into a comprehensive experience of thought, as opposed to just experiencing words on the page. Antigonick, in all of its iterations, becomes part of the active or participatory exchange required in the understanding of complex philosophical ideas. Theoretically, the intention is to have the performance itself become the philosophy as opposed to the idea that we read through the lens of philosophy ${ }^{10}$ and that the two are ultimately and inevitably always separate in their aims. I posit that the ultimate goal of Antigonick was to stage what theory could not adequately verbalize or to achieve the singular position of theory, which transcends the boundaries of language to become part of the embodied experience. But Antigonick manages to point a finger at the translative act as one involving performance. I propose, too, that the play in its performance makes a final and decisive comment about time: that performance and translation are both mired in it, defined by it, bound to it and that there exists an unrecognized bond of kinship between translation and performance and between performance and philosophy that calls for further exploration.

Part of the interest in translation and the timeliness of Carson's Antigonick is the short life of translation projects in the first place. These works quickly pass in and out of public consciousness. Even the outrage at Carson's liberties in exhuming the body of

\footnotetext{
${ }^{10}$ Laura Cull conjectures that philoperformance is not merely the application of philosophy to performance but the elevation of performance into the realm of philosophy so that neither takes precedence over the other (5).
} 
Antigone for public consumption has died down, replaced by praise for her newly published translation of fragments of Sappho or her reworking of bits of Proust. Projects in translation are subject to this ephemerality, and since, according to Derrida, it is the ability of a work to continue to be translated that keeps the work alive or that gives the project its hard-earned relevance, many more translators will try to fail better at the hands of translation projects. It is this very same sentiment that makes translation a bedmate of performance, since performance also suffers from this inevitable phenomenon at the hands of time. For many, even Derrida, the purpose of translation was to continue to keep a work relevant or to extend its life, but translation in Carson's hands does not have this illusion of immortality or this glimmering hope of its own unrivaled continuation. Translators take on the arduous task without the hope that theirs will be the translation that finally ends the demand for other translations. Necessarily, translation relies on time in the same way that successful performance does. They both take place in one specific moment when all of their disparate elements converge for a singular purpose, that is, to convey meaning to an audience in a way that bridges cultures and crosses languages. Invariably, translation and performance must arrive in the nick of time - unlike Haimon, Euridike, or even Kreon, who can acknowledge that the nick of time is at work, that time is clearly at play, but who cannot act within this small window to directly change the course of the action. "What is a Nick?” asks Euridike, before the messenger's announcement is made that her son has killed himself beside Antigone in protest (Sophocles and Carson 114). 
Granted, each new iteration of a work in translation is a short-lived revival of the source text, but these rebirths occur in bursts and they are defined by whether or not they bring with them a sense of an opportune mood, a sort of zeitgeist that most adequately gestures to the historically appropriate avenues for the translation itself. In some ways, this idea is reminiscent of Judith Butler's concept of cultural translation or the quest for some semblance of universality. In her Preface to Gender Trouble, Butler claims:

There is a new venue for theory, necessarily impure, where it emerges in and as the very event of cultural translation. This is not the displacement of theory by historicism, nor a simple historicization of theory that exposes the contingent limits of its more generalizable claims. It is, rather, the emergence of theory at the site where cultural horizons meet, where the demand for translation is acute and its promise of success, uncertain. (vi)

Note the use of translation as a vehicle for democratic change, not through a dialectic, but through the idea of transgression. Butler claims that the transgression of these cultural boundaries creates the propensity for some union or solution at some cultural horizon, where the ultimate goal or demand is communication and translation through and across culture(s).

Appropriately, Antigonick was released during a time of personal grief for Carson (who had just lost her estranged brother to illness) and during a mood of universal cultural grief for the circumstances of world politics. The Greek state was suffering from a political situation that threatened to throw all of the European Union into an economic tailspin (a crisis narrowly averted through bailouts). Meanwhile, Occupy Wall Street, the 
movement for economic equality in the United States, was in full swing. Carson and Robert Currie (the third collaborator on her project and her life partner) had, in fact, used a banner that read, "I was born to occupy love not hatred” (Anne Carson: Performing Antigonick YouTube) as part of a prop in their Louisiana staging of Antigonick - a banner that they carried around in protest through the street of New York City as they protested the lax restrictions and fines placed on the U.S. banks that caused the 2008 market collapse. As previously acknowledged, translation studies was also seeing a significant spike in interest amongst scholars for translation's ability both to be subsumed into the culture it enters and to question that very same culture. The implication here is that Antigonick arrived at just the right time, like its predecessors, to make a significant contribution to the socio-political stage in an attempt to tie together all of these divergent concerns. Antigone has long been read as a play about subversion, about standing up to absolute power. Antigone’s resistance becomes the resistance of the subjugated masses. Moreover, it is through the performance of Antigonick that further exploration of theoretical concepts and real-life application can come into play.

I've spoken about the theoretical implications of Antigonick and its position in the realm of translation studies as the bridge between translation and original, image and text, structuralism and post-structuralism. Now I attempt to place it between theory and performance, not with the desire to bridge the two, but instead to find a way to superimpose them - to collapse the division that has kept one from becoming the other. Translations, just like performances, inevitably carry with them the weight of every 
previous iteration, which is something that Carson performs by invoking names of previous translators and scholars of Antigone.

Still, there is a curious inconsistency that occurs in the text (and was mentioned briefly in the previous chapter) concerning Bertold Brecht's adaptation of Antigonick. I bring it up again now because I believe it is key to understanding the ways that translation and performance intersect. As far as Brecht's staging, we hear again and again from Carson’s own mouth in her letter to Antigone that maybe "Brecht got [Antigone] best” (“Anne Carson: Performing Antigonick,” YouTube) when he strapped a door to her back in the performance of his play. Now, there is no extant written account that cites a door strapped to any actress' back. There is no indication in the writing of the play itself (a technique Brecht was notorious for) and no critic or theatregoer makes any verifiable mention of this detail in any of the accounts of the play's success ${ }^{11}$. This fact makes the construction of Carson's sentence purposely misleading. No more did Brecht make Antigone perform the play with a door strapped to her back than Carson forces her literally to walk between life and death. What's worse is that critics and readers alike have failed consistently to pick up on the irony, citing the literal implications of imagining Brecht’s staging in this way.

The confusion between the literal and the figurative in this instance is powerful in its two-pronged commentary. First, this detail remarks on the precision with which a translator or anyone who works with the slipperiness of words must coordinate their language. But most importantly, this detail comments on the short-lived quality of

\footnotetext{
${ }^{11}$ Please see the Brecht Sourcebook edited by Henry Bial and Carol Martin.
} 
performance. Without a witness to record every verifiable detail, it seems that the play's original staging passes out of public memory and public consumption fairly quickly, enough so that a critic of theater and performance like Avital Ronell or Elisabeth Angel Perez did not bat an eyelash when they repeated the statement as an undeniable fact at the Sorbonne performance of Antigonick ${ }^{12}$.

With the bisection of translation and theater texts, theories of translation take on new levels of complexity as a result of the immediacy of their final iteration. BassnettMcGuire admits that this may be the reason why theater texts have been ignored in the grander scheme of translation studies altogether. Not only must the text in its twodimensional written form capture some quality of the original, but this quality must extend to its performance. In fact, I would go so far as to say that the performance and the written text are two separate versions of the same piece since they inhabit totally different spaces. A text that must be performed after it has been produced in translation is especially interesting since it is doubly performed. In her essay on the poems of Caroline Bergvall, critic Laura Goldstein writes, "Translation itself is a constant act of the performance of reading, writing and displaying language to an audience” (4) because an awareness of translation as the mode by which the text is rendered erases all possibility of smoothness or homogeneity. Like the Japanese practice of kintsukoroi creates a whole

${ }^{12}$ A quick look at Brecht's text shows that this interpretation by Carson is an image she more than likely derived from the play's diction. Brecht begins the play when Antigone and Ismene come home to find their front door standing ajar. From this moment on, the mention of the door occurs on 3 separate occasions, all as the result of connecting the idea back to that first door that started the course of the tragedy moving. In a figurative way, Antigone is tied to the door and the door becomes a symbol for her fate (a door is also a means of escape) (Brecht Malina 3). 
out of fragmented pottery with golden lacquer, Bergvall's project Via allows the reader to see the places where translation has attempted to smooth over a text. Likewise, Carson's project show us its edges by projecting snippets of Antigonick above the stage so as not to lose the effect of the material object in the shuffle, and it serves as yet another way of displaying language to an audience.

I have chosen two of the existing stagings of Antigonick found on YouTube in an attempt to unravel and clarify the stakes of pointing at this convergence between performance and translation. The first of these stagings was recorded at the Louisiana Film Festival on August 25, 2012, the second was produced on June 26, 2014 at the Sorbonne University's second annual philoperformance conference. These performances share the text in common, but their stage visions differ significantly. Thus, they create perfect vehicles for the study of performance since each varying vision is in itself a translation - an interpretation of Carson's text into a new medium. Each of the performances reify the idea that text in any stage of translation will inevitably find itself reworked to different ends. Taking Carson's own staging as the control, we can see the additions of further reworking the text at play in the immediate moment.

At the Louisiana Film Festival, Carson took a minimalist approach to her staging of Antigonick. In it, all actors wore black, and they strutted up to a single microphone to speak their lines as they held the pages of Carson's manuscript in their hands. They read out the lines in almost complete monotone, a detail that can easily be explained by the fact that no one on the stage - with the exception of Currie and Carson - speak English as their native language. In fact, it seems that Carson has recruited Danish and Swedish 
professors to drive home ideas about the lack of a universal language and what happens when the actors come to a latent understanding of what the words mean as they say them on stage.

The Sorbonne’s performance of Antigonick, which was briefly discussed earlier in this chapter, is important because it also stages Carson's minimalism with a few key exceptions, namely that of the audience functioning as the chorus (similar to the Greek choruses which were usually representative of the Greek city-states’ peoples). Subsequently, the actors were also the theorists recruited to impose meaning upon the text in a panel immediately following the performance. The most interesting casting choice was the one that left Judith Butler to play the role of Kreon. Butler, who is arguably the most notable theorist in issues of gender performance/performativity, stands in and visually enacts her own philosophy, deepening the tenor of her voice and emphasizing her own imposing power over Antigone (played by Avital Ronell) by standing with her legs apart and hands behind her back. Carson’s irony is easily picked up on by Butler and is performed by the inflections in her voice. All the while, the chorus (the audience) reads from scans of the text projected above the stage. Here we see the materiality discussed in the previous chapter haunting the staging of this version, forcing the text's importance upon an audience who is functioning as the polyvocality of the city - angry in protest over the death of Antigone. Ronell, Butler's counterpart, colleague, and foil, rushes through the first few lines of the play, in what looks to be her quickened reading as a result of the placing of Carson's words on the page. The Sorbonne reading, which incorporated prints of the book above the stage and which included the audience's 
reading of the chorus' lines thereby becoming active participants in the unfolding of the play's drama. This technique, according to critic Maggie Nelson, is characteristic of Bertold Brecht who was known for demanding "the spectator become more aware, via forced self-consciousness, of his or her complicity” (Nelson 24). The inclusion and transformation of the spectators into accomplices succeeds because of the staging and serves to steer the inquiry towards the enactment of Brecht's techniques.

In spite of this homage to Brecht and the multiple consistent mentions tobut am his Antigone, the key question remains: why does Carson include Brecht's adaptation but ignore Jean Anouilh's (or those of many other playwrights who have adapted Antigone through the ages)? Moreover, why position Brecht alongside Beckett as opposed to any of the other playwrights who have adapted Sophocles' original? Writing Beckett and Brecht as the only two dramatists in Antigonick is a move that positions Carson's adaptation between two radically different methodologies. On the one hand, there is Brecht's translation/adaptation of Antigone that relies on historicity, and on the other are Beckett's minimalistic productions, completely devoid of time and devoid of historicity in their execution. Brecht, as was mentioned before, used Holderlein’s rejected translation to reinvent the myth of Antigone into one that is situated temporally as part of the universe of the Nazi regime. The framework of Brecht's play was an "anti-fascist resistance” (Sipova Sarkassian 127), and his Antigone makes a comment on the political injustices of Brecht's time. An understanding of the historical context surrounding Brecht's original is vital. Moreover, Brecht's staging is, for the most part, a component of Antigone's own speech, meaning that it "delimits the actor's freedom of interpretation" 
(Puchner 155) thereby forcing the actors to perform the play exactly how he envisioned. In contrast, we have Beckett, whose only connection to Carson's project is that he might have “paraphras[ed] Hegel” (Sophocles and Carson 2), which in Carson's translation can very well mean that Beckett made a passing reference to Hegel once or that Carson thinks that the two of them would have made great card-playing buddies; the connections in her works are never as obvious as they appear. Still, whichever way we choose to understand this reference, it is undeniable that this mention of Beckett is the only other reference to a playwright directly or indirectly in the whole of Antigonick and that it raises significant questions about the desired comparisons.

The only other major touchstone of Beckett's work that intersects with Carson's agenda is his celebrated status as the poster boy for self-translation. Notorious for his need to control all aspects of his works, especially translations, Beckett was careful to supply all of them even if it meant tedious study in another language and the halting of all of his other work in progress - much to his editor’s chagrin. The most interesting aspect of Beckett's texts in translation is the fact that he purposefully rendered the changes present in them over time through the many languages in question so that the plays evolved parallel to his own evolution in thought. As a result, Beckett's characters became the "seers" of the future much like Tireisias or Antigone.

Time, which has been embodied in Carson's Antigonick, plays a crucial role in Laura Cull’s 2012 essay titled “Performance-Philosophy: The Philosophical Turn in Performance Studies (and a non-philosophical turn in Philosophy)," which attempts to clarify the role of Philoperformance as a way to create relations between performance 
and philosophy. She incorporates the philosophical work of Bergson and Deleuze as a philosophy of duration, where we measure out the duration of performances only through relations to others so that our "now" is only ever relative. In order for the theory of duration to make any sense, Cull says that one must experience it through performance. Doing so will inevitably force us to "understand waiting as an aesthetic activity" (Cull 8). For her thought-experiment, Cull calls on the understanding of ice melting in the hands of multiple active participants - the experiment becoming increasingly excruciating as one waits for everyone else's ice to melt. Likewise, Carson uses the image of melting ice in Eros: The Bittersweet to make a similar comment about time and the moment of desire as one that needs to be phenomenologically situated. We must experience the ice melting to understand our own desire. Carson adds that writing is an attempt to "render things clear and fixed for all time” (121); therefore, we must assume that performance with its limited time span and momentary execution is a way to enact what Carson cannot through writing, a way to show us how "language is embedded in this moving process [of time]" (120) - that it, too, is transient. Antigone, who walks the line between life and death as the result of tragedy, moves through both realms while belonging to neither.

When Carson lists Kreon’s verbs, it is “capitalize” (Sophocles and Carson 15) that stands out most, since his obsession with the exploitation of power is mirrored in our own economy - or maybe it is his singlemindedness about capitalization, about proper names and property. Either way, Antigone's response to Kreon's bullheaded desire to extend time to suit his own self-important monologue is curt: "can we just get this over with?" (Sophocles and Carson 27) she asks like a teenager, impetuously, without a second 
thought to the verdict announcing her death because she just wants to halt this onslaught and cut right over to the end of the tragedy. Antigone's concept of time, as the result of her foresight, is more like the prophet Cassandra's than anything we can imagine as belonging to Oedipus' daughter. She is the only character fully capable of acknowledging and accepting the inevitability of time while simultaneously collapsing it by referencing past and future at the same time.

It was Virginia Woolf who imagined time as "the folding of papers making up a book - a folded text which must be unfolded in the process of extracting discrete memories” (West-Pavlov 237). That image recalls the enacting of time in Carson's Antigonick as well as the materiality of the book itself. Similar to Woolf, physicists have imagined time as a manipulable dimension that can be folded over and into itself. Furthermore, it is through the study of black holes that we have come closer to understanding that time is not set on a clear unidirectional course, but that, like Antigonick, time can make the "future plung[e] towards" us (Sophocles and Carson 56). Like Antigone, who is living her final moments on stage, we can be both dead and alive, both autonomous and subjugated, and all of our motion is movement towards that other moment in time, not through a series of unilinear steps but by jumping in and out of time. 


\section{CONCLUSION}

Antigonick opens with an assertion: "we begin in the dark and birth is the death of us” (Sophocles and Carson 4), a prophecy that predicts the play’s ending before it has begun. From this opening line throughout the rest of the play, the audience receives a proleptic history of Antigone’s character in the vein of Shakespeare’s “Seven Ages of Man,” all the while expecting that the curtain will fall and the tragedy will be over plunging characters towards the end that their birth on stage signals. This cycle of birth and death, of tragedy played out for an expectant audience, can easily apply to the creation of a translation. It was Derrida, who called translation a tragedy (Ertel 9). It is Carson who arranges, stages, and enacts this tragedy through her eclectic pastiche of words, images, and performance. Carson comments on the state of translation studies in order to usher a wave of change and active movement towards new ways of representation. But before any action can be undertaken, Carson must be formally recognized as a translator working and immersed within the discourse of translation studies.

The task of the translator is, at its core, the recognition of the need for translation in the present. The product of translation or the translation itself has only a momentary afterlife, unlike the more ambiguous and unlimited afterlife that Derrida claims in "What is a Relevant Translation?” (Derrida “What is a Relevant Translation?”). Works in translation arrive at a moment when they are needed and recede from popular consciousness just as quickly in order to make room for some other more timely iteration. For Carson, translation is attached to cultural impetus, a point that Ben Hjorth makes when he states that "a contemporary translation must heed this demand of the new: that 
which inheres in the language of the present, that which demands to be spoken, that which demands to be responded to, through and by the mythic figures translated and transformed in performance” (Hjorth 139). Figures such as Brecht or Heidegger all signal the past and bring with them the rich history of Antigone as character and as symbol. For Carson, this acknowledgement concedes that she is invested in epistemic history enough to know and recognize the "etymology of drama" (a collection of actions or doings) that conjures the long tradition of Antigone's catastrophic family and that, at present, includes this Hegelian academic and philosophic genealogy (“Anne Carson: Antigonick”).

Translation as such is inexorably linked to time and place. For Antigonick, the historical moment of Carson's translation was a time when Greece was shaken by its financial crisis. It was a time when Russian translators were rediscovering Western classics and translating them at will, reorganizing and often times rewriting them with a liberal political agenda. Domestically, it was a moment when people were taking to the streets to demand economic equality in the United States. The Occupy Wall Street movement gathered momentum and came to its height right before the publication of Carson’s Antigonick. In fact, the connection between Carson and this movement was already made by Becky Cremin in a book titled "Public Poetics: Critical Issues in Canadian Poetry and Poetics,” which read Carson's Antigonick as a call to arms for a more peaceful yet proactive community that could change global politics through poetry (Verduyn et.al.). Carson herself endorsed this

Although I find myself talking about this particular moment in the past tense, as performance and text that has passed out of cultural memory, I am not sorry to say that 
Antigonick served to highlight this instant of cultural transgression and that it stands as yet another moment of Carson’s particularly capacious brilliance. Because, as Antigonick has demonstrated, time has the potential of folding over onto itself so that all we must do is revisit Antigone with a mind to the present in order to find its cultural relevance. For that exercise, we can imagine Antigone standing in for these same struggles of inequality that plague our society now.

The point of this thesis was not to offer up one interpretation of the elements in Carson’s Antigonick. To do so would counter what Carson has put forth for our consideration. Instead, this thesis points out what Carson called the "crack of light showing under the door of a room where [she’s] been locked for years” (Nox 48) or, in other words, that bit of work, brought about by Eros or stereoscopy, that consistently defies categorization and which brings a translator closer to whatever makes a translation truly relevant. The elements that are, as the cliché goes, lost in the translation, and that become part of this great existential Babel that can seem insurmountable, though writers, readers, and translators try to reach up and touch its great peak anyway. Such is the plight of desire.

It is time that makes fools of us all, and is this not the final message of the play? At the end of Antigonick, once all characters have met their fate, the final stage direction in brackets reads, “exeunt omnes except Nick who continues...measuring” (Sophocles Carson 103). Time remains on stage measuring a history that we can only inhabit for a moment, an image that stands arrested in movement, and a translation that is only relevant once. Wisdom, we would do well to acquire it, even if it is too late. 


\section{BIBLIOGRAPHY}

"Anne Carson: Antigonick." Interview by Alex Anne Carson: Antigonick. Anne Carson: Antigonick. SASH: Los Angeles 29 July 2012. Print.

"Anne Carson: Performing Antigonick." YouTube. Louisiana Channel, 3 Feb. 2013. Web. 22 Feb. 2016.

"TPP2014 : Public Reading of Antigonick by Anne Carson at Sorbonne University." YouTube. Ed. Ben Hjorth. Sorbonne University, 4 Sept. 2014. Web. 01 Feb. 2016.

"Staging Theory: Theatricality and the Displacement of Desire". "Staging Theory: Theatricality and the Displacement of Desire”. Performance Degree Zero: Roland Barthes and Theatre. University of Toronto Press, 2006. 97-135. Web.

Bai, Xuefei. "Woman and Translation: Beyond the Myth of Europa." Selected Papers of the CETRA Research Seminar in Translation Studies 2009 (2010): 1-17. University of Massachusetts Amherst. Web.

Bassnett, Susan, and Andrâe Lefevere. Constructing Cultures : Essays On Literary Translation. Clevedon: Multilingual Matters, 1998. eBook Collection (EBSCOhost). Web. 1 Feb. 2016.

Bassnett-McGuire, Susan. Translation Studies. London: Routledge, 2002. Print.

Benjamin, Walter. "The Task of the Translator.” Theories of Translation. Ed. Rainer Shulte and John Biguenet. Chicago: The University of Chicago Press, 1992. 71-82. Print.

Brecht, Bertolt, Judith Malina, and Sophocles. Sophocles' Antigone. New York, NY: Applause Theatre Book, 1990. Print.

Butler, Judith. Gender Trouble: Feminism and the Subversion of Identity. New York: Routledge, 2006. Print.

Camille, Michael. Image on the Edge: The Margins of Medieval Art. London: Reaktion, 1992. Print.

Carson, Anne, Aeschylus, Sophocles, and Euripides. An Oresteia. New York: Faber \& Faber, 2010. Print.

Carson, Anne. Eros the Bittersweet. Champaign: Dalkey Archive, 1998. Print. 
Carson, Anne. If Not, Winter: Fragments of Sappho. Vintage, 2003. Print.

Carson, Anne. Men in the off Hours. New York: Vintage, 2001. Print.

Carson, Anne, and Gaius Valerius. Catullus. Nox. New York: New Directions, 2010. Print.

Carson, Anne. "Variations on the Right to Remain Silent." A Public Space 7: 1-11. Poetry Daily. 2008. Web. 4 Feb. 2016.

Chattopadhyay, Arka. "Jacques Derrida and the Paradox of Translation: "You Must Go On. I Can’t Go On. I Will Go on." University of Calcutta Conference (2010). Print.

Cull, Laura. "Performance-Philosophy: The philosophical turn in Performance Studies (and a non-philosophical turn in Philosophy)", unpublished conference paper at Performing Research: Creative Exchanges, Central School of Speech and Drama, London, UK, 19-20 January 2012.

Derrida, Jacques. "Des Tours De Babel." Trans. Joseph F. Graham. Difference in Translation. Cornell UP, 1985. Print.

Derrida, Jacques. Monolingualism of the Other, Or, The Prosthesis of Origin. Stanford, CA: Stanford UP, 1998. Print.

Derrida, Jacques. "What Is a 'Relevant’ Translation?" Trans. Lawrence Venuti. Critical Inquiry 27 (Winter 2001). The University of Chicago. Web.

Derrida, Jacques, and Christie McDonald. The Ear of the Other: Otobiography, Transference, Translation: Texts and Discussions with Jacques Derrida. Lincoln: U of Nebraska, 1988. Print.

DuBois, Paige. "Toppling the Hero: Polyphony in the Tragic City." New Literary History: A Journal of Theory and Interpretation (2004): 63-81. ProQuest. Web.

Ertel, Emmanuelle. "Derrida on Translation and His (Mis)reception in America." Revuet Trahir 2 (September 2011): 1-18. Web. 31 Jan. 2016.

Goldstein, Laura. "Translation as Performance: Caroline Bergvall's Via." HOW2. Arizona State University. Web. 01 Feb. 2016.

Jong, Irene J. F. De., and Albert Rijksbaron. Sophocles and the Greek Language: Aspects of Diction, Syntax and Pragmatics. Leiden: Brill, 2006. Print.

Kearney, Richard. Modern Movements in European Philosophy. Manchester: Manchester UP, 1994. Print. 
Martin, Carol, and Henry Bial. Bertolt Brecht: A Critical Anthology. London: Routledge, 1999. Print.

Middleton, Kate. "'An Interesting and Valuable Mental Event': Anne Carson's 'Error Poetics.'" Order No. 1465457 Georgetown University, 2009. Ann Arbor: ProQuest. Web.

Nelson, Maggie. The Art of Cruelty: A Reckoning. New York: W. W. Norton, 2012. Print.

Proctor, Nathan. "The Space in Between, For Example." Columbia Journal of Literary Criticism 11 (2015): 14-21. Print.

Puchner, Martin. Stage Fright: Modernism, Anti-theatricality, and Drama. Baltimore: Johns Hopkins UP, 2011. Print.

Reynolds, Jack, and Jon Roffe. Understanding Derrida. New York: Continuum, 2004. Print.

Schulte, Rainer, and John Biguenet. Theories of Translation: An Anthology of Essays from Dryden to Derrida. Chicago: U of Chicago, 1992. Print.

Šipová, Pavlina N., and Alena Sarkissian. Staging of Classical Drama around 2000. Newcastle, UK: Cambridge Scholars, 2007. Print.

Smyth, John Vignaux. A Question of Eros: Irony in Sterne, Kierkegaard, and Barthes. Tallahassee: University of Florida, 1986. Print.

Söderbäck, Fanny. Feminist Readings of Antigone. Albany: State University of New York Press, 2010. Print.

Soloski, Alexis. "Greek Tragedies Lost in Anne Carson's Translation." The Guardian. 27 Apr. 2009. Web.

Sophocles, and Anne Carson. Antigonick. New York: New Directions, 2012. Print.

Sophocles, and Paul Woodruff. Antigone. Indianapolis: Hackett Pub., 2001. Print.

Steiner, George. After Babel: Aspects of Language and Translation. Oxford: Oxford UP, 1998. Print.

Steiner, George. "Anne Carson 'Translates' Antigone." The Times Literary Supplement. 1 Aug. 2012. Web.

Steiner, George. Antigones: How the Antigone Legend Has Endured in Western Literature, Art, and Thought. New Haven: Yale UP, 1996. Print. 
Stennett, William H. A History of the Origin of the Place Names Connected with the Chicago \& North Western and Chicago, St. Paul, Minneapolis \& Omaha Railways. Leopold Classic Library, 2016. Print.

Venuti, Lawrence. "Translating Derrida on Translation: Relevance and Disciplinary Resistance." The Yale Journal of Criticism 16.2 (2003): 237-52. Project Muse. The Johns Hopkins University Press. Web.

Verduyn, Christl, Erin Wunker, Travis V. Mason, and Bart Vautour. Public Poetics: Critical Issues in Canadian Poetry and Poetics. Wilfrid Laurier UP, 2015. Print.

Wakabayashi, Judy, and Rita Kothari. Decentering Translation Studies: India and Beyond. John Benjamins, 2009. Print.

West-Pavlov, Russell. Space in Theory: Kristeva, Foucault, Deleuze. Amsterdam: Rodopi, 2009. Print. 


\section{APPENDIX}

Image 1: Precedes the title page. Cavern or canyon. Colors used: black and light blue. You can see the title page through the vellum.

Image 2: Two elongated human-like figures are letting go of each other's hands. The figure walking away from the reader has two eyes and a mouth, the one in the foreground has a body covered in black smudges - its face completely indiscernible. Seems to be looking out towards the other figure. A border surrounds the image, demarcating it and preventing complete immersion into the background. Colors: black and red. After this image, chorus speaks.

Image 3: Five figures stand side by side - three of them seem to be women, two are men. They all have cement blocks floating above their bodies where their heads should be. No neck connects the makeshift heads to their torsos.

Image 4: Spoons, knives, and forks sit inside what looks to be an iron cast cup. A spool of orange-red string sits outside of the pot and ties all the utensils together. A spoon seems to be floating away from the rest of the items. It is the only one not tied by the string. Following this image, talk of brothers and Kreon's power.

Image 5: Large spool of the very same red-orange thread. String leads into the foreground. No border. Image stands embedded in the vellum. List of nouns Kreon uses to describe power come afterwards.

Image 6: This image seems to illustrate a canyon with a river running through the center. Image 7: Mountainous, craggy terrain. Sky dots the background. Foreground of the image contains what looks to be a three tiered wedding cake in the bottom right corner. The only words that poke through are "This" at the top left and "customer” in the bottom 
center. What appears to be a waterfall splashes from one of the hills onto some rocks below.

Image 8: Two spools, one of average height and one $1 / 4$ the size of the first adorn the page. A needle is attached to the thread of the larger spool. There is no color in this image. The chorus (ode to man) can be seen through the vellum of the page.

Image 9: A large black chair with a tear in the seat from which one cannot tell where the seams start/end. It is almost as if the seat has been lifted from the backing to reveal the filling.

Image 10: A wave coming at a small powerboat while a horse figure swims away (vaguely looks both human and horselike). The boat looks like it has just been overturned and the figure looks as if he/she/it has just fallen out. The figure is swimming towards the wave and away from the boat.

Image 11: A building that looks like a barn made of planks of wood is depicted. It has one circular window at the tallest part of the structure and an adjoining section that looks like an outhouse. From the bottom of the outhouse, two legs stick out and bend in opposite directions as if someone was kneeling and then suddenly fell asleep. Birds (or bats) dot the skyline. A fence spans the background and recedes into the horizon.

Image 12: Takes place inside of a house, possibly a living room. Blue tiles and the sight of blue mountain skyline through a window directly ahead. In the foreground is a yellow chair sitting on the corner of a pink flowery mat. The back left corner boasts a curio with books and wine glasses next to a radiator. On the sill is a withering plant turned sideways. Domestic setting. Words you see through the vellum are: think, guilty, girl. 
Image 13: Two pictures, bordered and framed as if they were sitting in an album. The top image is of a canyon in a desert. A tiny figure walks between the two flanking rock formations. One cannot make out if the figure is male or female but it is walking away down a path that runs through the middle of the formations.

The bottom image is host to two figures huddle together in the bottom left foreground. One of them wears what looks to be a football helmet and is a bit taller than the figure next to it with hunched shoulders. A path is ahead of them, one that seems to run through the very same formations as the first. Is this the beginning of the journey? Is this the end? On the next page, the two sisters are debating whether or not one should take the fall for the other's crimes.

Image 14: A long table is spread. One participant sits on the opposite end of the reader (as if the reader was at one head of the table and the other person sitting directly across from him/her). The table has a middle stripe in green/yellow. The yellow splotches appear to be serving plates. 18 places are set all around the table with cups and plates. Image 15: The tall part of the house from Image 11 reappears here separate from the outhouse. Smoke comes out of a chimney at the top, clouds that look like birds dot overhead. Everything is in black and white.

Image 16: A horse, colored in with yellow/pink watercolors is being carried off towards the right side of the image by a large figure dressed in black. The figure looks to have no head (if he/she does, it is off-image and disproportionate to the figure). In the center of the image is a black splotch of paint. 
Image 17: Two images on one page, much like those in Image 13. Here, the background of the images is mostly black. The top one includes a bed with checkered quilt sheets where you can clearly see the connective stitching.

In the bottom image, two genderless figures, one with its mouth agape, the other with clenched teeth touch foreheads while they sit on a quilt that looks a lot like the bed in the image above them. The figures have no distinguishing features other than their faces and their bodies are comprised of the blank space that comes from the vellum in the background.

Image 18: This is a busy painting. The faces look grieved, sad, or downcast. Seven human-like figures are strewn in various positions on the page. In the background, two men one woman, a horse, and a figure that stands behind one of the men with a cinderblock for a head. The middle ground of the painting features a man with downcast eyes, a cinder block figure holding a shovel and another cinder block figure turned sideways dressed in blue. The foreground hosts an amorphous figure with his back to the audience and hand resting on the shoulder of another cinder block headed person to his left. In the bottom right corner, there is a book on a mat and what appears to be a pen or a tiny hook/hoe.

Image 19: A sink is propped up against a tiled wall. Both faucets are turned on and the water runs into the basin and down the drain. Above the tiles, as if placed on a ledge on top of the faucet is the body of a person lying sideways with the soles of their feet facing towards the audience. 
Image 20: A conventional kitchen stove sits in the center of the image, tilted slightly to the left. The stovetop houses a yellow teakettle and a frying pan. Closest to the reader is what looks like the pink rug from Image 12, frayed at the edges.

Image 21: At a table, a horse with an open mouth sits in an active/dynamic position. On the table, a glass of wine spills over but not onto the floor. Things are caught arrested in movement. The table is set for three people. One plate has tiny dead fish with x's for eyes. The horse's plate has fish and peas. The seat closest to the reader is empty, but a plate still sits on the table in front of it. A fish head (the largest of all the ones on the table) is placed directly in front of the seat closest to the reader. Underneath the table are a wine glass in the process of spilling and some bananas.

Image 22: A parallel line bisects the body of a horse in movement. The top half of the horse does not appear. Only part of the torso and the hooves are visible. The horse's front hooves are tied with the string from a red spool. He seems to have a needle/arrow head sticking out of the front hoof. Through the top portion of the image, one can see the words "no not really". Through the bottom portion, "here comes tireisias" announces the arrival of the blind prophet.

Image 23: Mountains and hillsides, everything blends into itself. Nothing more memorable or more seemingly significant than the other in this scenario?

Image 24: Close up on a section of a gray wall with black molding. Here, there is an outlet with something plugged into it. The chord leads up to the corner of a table where what looks to be a lamp is attached. The reader can only see the left corner of the lamp and of the table. On the next page, the chorus talks about time. 
Image 25: Glimpsing into what looks to be a regular living room in any dorm/apartment. On the left hand side, there is a tiny hallway with a bookcase that leads towards a front door hanging ajar. To the left, there is another door that opens towards the reader. Nothing can be seen inside this room and what little the viewer can see is just black. Positioned on the wall between both doors is an assortment of rather mundane looking items: a calendar with what looks to be Image 1 over the word 'December', also some pictures in frames where the figures in them appear to be very generic amorphous humanlike creatures akin to the ones seen before throughout the book. Spliced in at the center of the living room is a square image with a biped humanoid creature holding a shovel sideways. The background of this image insert is black and red.

Image 26: Shovel against a blank background.

Image 27: A golden staircase sits in the foreground of an image of mountains/crags. At the top of the staircase, the reader can see two feet attached to legs. The figure looks to be laying down parallel to the reader but we cannot see anything past their legs.

Image 28: Mountains in black and white. On the left hand of the bottom part of the image are three alien creatures that look like wisps of smoke. Two chairs sit empty and dwarfed by the mountains in the background.

Image 29: Hanging ladder arrested in midair.

Image 30: Busy image. A horse with three heads stands in the center of a grassy setting. It's not so much that the horse has three heads, as it seems to be a horse in slow motion throwing its head back being caught by a camera over the course of a few seconds.

Image 31: Three figures with women’s bodies walk beside each other in this image. They wear uniform outfits of yellow/blue tops with yellow and white pleated skirts. Their 
midriffs are showing and their skin is a bright pink. Where their heads are supposed to be, cinder blocks with 3 square cutouts are suspended above their shoulders. There seems to be no neck connecting the cinder heads to the female bodies.

Image 32: A flock of birds outlined in black fly off the page, one of which hangs out on the top left corner of the page away from the rest.

Image 33: Once more, we have the solitary figure walking between two cliffs. As readers we are closer to the figure who is still far enough away that it is only the vague imagining of a person - very easily confused with a splotch of black paint.

Image 34: There is nothing on this page of vellum. Through it, one can see the words “[exeunt omnes except Nick who continues measuring. 